\title{
Dietary long-chain omega-3 fatty acids of marine origin: a comparison of their protective effects on coronary heart disease and breast cancers
}

\author{
Sébastien Judé*, Sébastien Roger, Eric Martel*, Pierre Besson, Serge Richard*, Philippe \\ Bougnoux, Pascal Champeroux*, Jean-Yves Le Guennec
}

Université de Tours; Inserm E 0211, Nutrition, Croissance et Cancer; Faculté de Médecine, 10 Bd Tonnellé, 37032 Tours Cedex (France). *Centre de Recherches Biologiques, Chemin de Montifault, 18800 Baugy (France)

Corresponding author:

Jean-Yves Le Guennec

Université de Tours, Inserm E 0211, N2C

Faculté de Médecine

10 Bd Tonnellé

37032 TOURS Cedex (France)

Tel: (+33) 247366130

Fax: (+33) 247366226

Email: Jean-Yves.LeGuennec@Univ-Tours.Fr 


\section{ABSTRACT}

The relationship between high fish consumption and low mortality following coronary heart disease (CHD) and low incidence of breast cancer was first mentioned 3 decades ago. The fishes of interest are rich in omega-3 long-chain polyunsaturated fatty acids ( $\omega$-3 LC-PUFAs), especially eicosapentaenoic acid (EPA) and docosahexaenoic acid (DHA), which could be the active nutrients. The current consensus about cardioprotection is that $\omega-3$ LC-PUFAs would mainly exert antiarrhythmic effects. One of the proposed mechanisms is that circulating non esterified LCPUFAs partition into cardiac cells membrane phospholipids and exert a direct effect on ionic channels and/or modify intracellular calcium homeostasis. In another hypothesis, changes in the metabolism of phosphoinositides would be involved and lead to the differential activation of PKC isoforms. As compared to the mechanisms proposed for the cardioprotective effects of omega-3 LCPUFAs, less is known about the molecular mechanisms involved in breast cancers prevention. Some proposed mechanisms such as the modulation of phosphoinositides metabolism and/or modulation of intracellular calcium homeostasis, are common to both pathologies. Other hypotheses involve the alteration of the cellular redox status induced by highly peroxidizable polyunsaturated fatty acids, or the modulation of gene expression, both phenomena being tightly linked to apoptosis. In this review, we report and compare some proposed mechanisms for the involvement of omega-3 LC-PUFAs in both cardiac and breast cancer protection. Deliberately, we chose to discuss only the mechanisms which are less described in other reviews such as ionic channels in cancer, calcium homeostasis, PKC activation or matrix metalloproteinases in both cancer and cardiac models. The leitmotiv along this review is that cardio- and cancero- protective effects use common pathways. Comparison of the cellular effects might therefore help to highlight the "protective" pathways.

Keywords: breast cancer, coronary heart disease, omega-3 polyunsaturated fatty acids, signalling pathways. 


\section{INTRODUCTION}

The inverse relationship between high fish consumption and low mortality following CHD or breast cancer was first mentioned 3 decades ago. The fishes of interest are mainly oily fishes (e.g. wild salmon, sardines, mackerel) which are rich in omega $3(\omega-3)$ LC-PUFAs. The two fatty acids (FA) which are very likely to be involved in the beneficial effects of fish oils are eicosapentaenoic acid (EPA, C20:5n-3) and docosahexaenoic acid (DHA, C22:6n-3). These FA are produced by monocellular algae or phytoplankton which represent the beginning of the food chain, and accumulate in the flesh of marine fishes. In this review, we do not address the field of alphalinolenic acid since this fatty acid has a vegetable and not marine origin.

The first evidence for cancer- and CHD-protective effects of fish consumption came from epidemiological studies on Inuit and Japanese populations which, in their country of origin, mainly eat fish (Buell, 1973; Bang et al., 1976). When these populations migrated and adopted the local food habits, the disease incidence increased to reach the one of the local populations, ruling out genetic protection.

It is well known that the effects of $\omega-3$ PUFAs are generally opposite to those of $\omega-6$ PUFAs (mainly arachidonic acid, AA: C20:4n-6). They compete for the same cyclooxygenase, lipoxygenase and epoxygenase enzymes to form different classes of eicosanoids. Members of each class have opposite effects, depending on the initial substrate, $\omega-3$ or $\omega-6$ LC-PUFAs (Weber et al., 1986; Bagga et al., 2003).

While eicosanoids can participate to some beneficial effects of $\omega$-3 LC-PUFAs, they cannot explain all the protective effects of these PUFAs on cardiac function following CHD and on breast cancers. Thus the aim of the present review is to compare the effects of $\omega-3$ LC-PUFAs on some ischemic cardiac dysfunctions and on breast cancer in order to evaluate if some of the beneficial effects involve similar signalling pathways. 


\section{I - EPIDEMIOLOGICAL STUDIES}

At the end of the 1970's, it has been observed that Inuit population had a lower incidence of cardiac diseases than the Dane population (Bang et al., 1976). At the same period, it was observed that Japanese women had a lower risk to develop a breast cancer than women in other industrialised countries (Buell, 1973, see figure 1A). Also, the incidence of cardiovascular diseases in the Japanese population is low (Kagawa et al., 1982). All these observations have been attributed to high fish consumption by these populations (Kromhout et al., 1985; Wynder et al., 1986). Rapidly, the interest of researchers focused on the possible protective effects of marine $\omega-3$ LC-PUFAs, namely EPA and DHA (see figure 1B).

\section{I-1 - Epidemiological studies on cardiovascular diseases}

The first clinical cardiovascular trial was reported in 1989 (Burr et al., 1989). The authors showed that the mortality following myocardial infarction was reduced by $29 \%$ after two years in a group of men who were advised to eat oily fishes at least twice weekly as compared to others who had not received any recommendation. This reduced mortality was not associated with reduced ischemic heart disease events or levels of total cholesterol. This suggested anti-arrhythmic effects since arrhythmias are likely to be the main cause of sudden death following myocardial infarct.

More recently, a large prospective, randomized clinical trial of 11324 patients who had had a recent myocardial infarction was reported (GISSI, 1999). In this trial, patients were randomly assigned to four groups to test the effects of a daily dose of 1) $850 \mathrm{mg}$ EPA plus DHA (inferior to the recommendation of $1000 \mathrm{mg}$ per day by the American Heart Association; Kris-Etherton et al., 2002), 2) $300 \mathrm{mg}$ of $\alpha$-tocopherol (vitamin E, an anti-oxidant), 3) $\omega$-3 PUFAs plus vitamin E and 4) a control group that received neither fatty acids nor vitamin E. This supplementation was in addition to the pharmacological treatment. After 3.5 years, vitamin E did not bring significant benefits while $\omega$-3 LC-PUFAs lowered the risk of cardiovascular death by 17\% (2-ways analysis) or 30\% (4-ways analysis). A $45 \%$ reduction in sudden death at 42 months, which started to be significant 4 months 
after the beginning of the supplementation, was also observed (Marchioli et al., 2002). This latter observation strongly suggests that the benefit of $\omega-3$ LC-PUFAs may not be mediated via antiatherosclerotic and antithrombotic effects but very likely involves anti-arrhythmic effects. Another prospective randomized trial reported a 50\% reduction of the risk of sudden cardiac death with higher doses of $\omega-3$ LC-PUFAs (2 g per day EPA plus DHA) (Singh et al., 1997).

\section{I - 2 Epidemiological studies on breast cancer}

The influence of environmental factors such as diet on breast cancer is an accepted fact (Buell, 1973; Word Cancer Research Fund, 1997). Despite the promoting effects of total dietary fat on breast tumours, it has been shown that $\omega$-3 LC-PUFAs were lacking tumour-promoting effects (Wynder et al., 1986). Since these pioneer works, many epidemiological studies have been undertaken to document further a protective role of $\omega$-3 LC-PUFAs but they remained inconclusive (Willett, 1998). The discrepancy may arise from confounding effects of many compounds such as antioxidants or $\omega-6$ LC-PUFAs which both can be cancer promoting agents (Bougnoux, 1999). Above all, it must be underlined that the relative proportion of $\omega-3$ and $\omega-6$ LC-PUFAs may be a determinant of the effect of $\omega-3$ LC PUFAs on breast cancer risk (Chajès \& Bougnoux, 2003). Indeed, a recent European case-control study gave results leading to the hypothesis that $\omega$ - 3 LC PUFAs inhibit breast cancer, depending on background levels of $\omega-6$ LC-PUFAs (Simonsen et al., 1998).

\section{I - 3 Conclusion on epidemiological studies}

From the epidemiological studies, it appears that the cardioprotective effects of fish oil $\omega-3$ LC-PUFAs are well determined while the anti-tumoral effects need careful settings and characterizations of other components of the diet such as $\omega-6$ PUFAs and antioxidants levels. These differences might be due to the fact that the causality of the disease is well defined in the case of the heart (mortality following myocardial infarction) while the etiology of breast cancer is 
multifactorial. Indeed, it is even critical to recognize that breast cancer is a collection of diseases (Debies \& Welsh, 2002).

\section{II - EXPERIMENTAL STUDIES}

\section{II - 1 Experimental studies in cardiology}

The first study investigating the possible antiarrhythmic effects of fish oil fatty acids was performed in 1988 by McLennan et al. In their experiments, rats were fed diets in which the major fat component was controlled. At the end of the 3 months dietary period, they ligated the left anterior descending coronary artery of the rats and counted the number of animals that died of sustained ventricular fibrillation. They found that, while some rats died of arrhythmias in the group receiving sunflower seed oil, no rat died in the group receiving tuna fish oil (rich in $\omega-3$ LC-PUFAs). They also reported a similar antiarrhythmic action of the $\omega-3$ LC-PUFAs in marmosets (McLennan et al., 1992). Similar results have been obtained in rats by other investigators.

To investigate a possible direct effect of $\omega$-3 LC-PUFAs on ischaemia-induced ventricular fibrillation, Billman et al. (1999) used another approach to supply the fatty acids. A surgically induced anterior myocardial infarction was produced in dogs, and a hydraulic inflatable cuff was set around the left circumflex artery so it could be compressed at will. The dogs were then trained to run on a treadmill during the month allowed for recovery from the surgery. Upon exercise, the coronary occlusion caused about $60 \%$ of the dogs to go into a fatal ventricular fibrillation within two minutes of the coronary flow stop. The intravenous administration of EPA or DHA (free FA) 90 minutes before the exercise reversibly prevented fatal ischaemia-induced arrhythmias, confirming the studies of McLennan et al. (1988, 1992).

However, a difference remains between Billman's and McLennan's results. In their work, Billman et al. (1999) did not find any difference between the antiarrhythmic effects of EPA and DHA in dogs. McLennan et al. (1996) compared the effect of low dose (0.4 - 1.1\% of energy 
intake) of EPA and DHA on rat ischaemia-induced arrhythmias. They found that DHA was able to prevent these arrhythmias while EPA was not. The difference between the results could originate from the way of administration of the oils: in one experiment, FA were administered in the diet while in the other, they were perfused intravenously. An other hypothesis relies on the model used. Indeed, it is not obvious that lipid metabolism is the same in rats and dogs. This point is a very important one and has to be clarified before extrapolating results obtained in animals to observations made in human epidemiological studies.

\section{II - 2 Experimental studies in breast cancer}

Data from experimental studies carried out in animals show that elevated supplies of fish oil (rich in EPA and DHA) generally inhibit tumour growth in chemo-induced, transplanted or spontaneous mammary tumour models (for a review see Bougnoux, 1999; Rose \& Connolly, 1999). A meta-analysis by Fay et al. (1997) showed that $\omega-3$ LC-PUFAs have only a small protective effect while $\omega-6$ PUFAs have a strong tumour-enhancing effect. Like in epidemiological studies, the ratio $\omega-6 / \omega-3$ PUFAs seems to be primordial to observe an effect, a ratio of 1 being protective while higher ratios are tumour-enhancing (Cohen et al., 1993; Sasaki et al., 1998).

Another aspect of breast cancer is the occurrence of metastases. In models of mammary cancer cell lines transplanted into nude mice, it has been observed that EPA and fish oil diet supplementation reduced primary tumour growth and metastases occurrence (Senzaki et al., 1998; Hubbard et al.; 1998).

\section{II - 3 Conclusion on experimental studies}

As in epidemiological studies, the cardioprotective effects of $\omega-3$ LC-PUFAs appear obvious, probably owing to the well-defined models of cardiac disease. In animal models of breast cancer, even if the situation is not as clear as it is in cardiac models, the protective role of 
$\omega$-3 PUFAs seems very likely but this effect is hampered by the tumour-enhancing effects of $\omega-6$ PUFAs and antioxidant also present in the diet. Moreover, it seems that the ratio $\omega-6 / \omega-3$ is more important than the mere $\omega-3$ intake.

\section{III - CELLULAR EFFECTS}

\section{III - 1 Cardiac effects}

At the cellular level, the results obtained on the cardioprotection effects of $\omega$-3 LC-PUFA were mainly obtained by Leaf and collaborators on cultured neonatal rat cardiomyocytes. In brief, they found that the arrhythmias produced by high extracellular calcium concentration, ouabain, isoproterenol, lysophosphatidylcholine and even the $\mathrm{Ca}^{2+}$ ionophore $\mathrm{A} 23187$ were reversed by EPA (see figure 2). This effect was reversed by the addition of delipidated bovine serum albumin to remove free acids from the myocytes. It must be noted that this effect was observed with the free acid while the ethyl ester of EPA was ineffective (see Leaf et al., 2003 for a review). These results led Leaf's group to hypothesise that the free fatty acid, thanks to its carboxylic group, interacts directly with ionic channels to prevent or resorbe lethal arrhythmias.

\section{III - 2 Breast cancer cells}

While the in vivo (epidemiological and experimental) studies did not give strong evidence for a beneficial effects of $\omega$-3 LC-PUFAs against breast cancer, in vitro cell culture experiments have led to a consensus that some PUFAs have a selective cytotoxic or anti-proliferative effect on tumour cells and no effect on normal cells. However, this consensus has been challenged in a recent and pertinent review (Diggle, 2002). Indeed, in studies on MCF-7 cells, Grammatikos et al, (1994) showed that the proliferation of these cells was inhibited by $\mu$ M EPA, but also by AA. Such an inhibition was not observed by Chajès et al (1995) but in this latter study, other cell lines (MDA-MB-231, HBL-100, ZR-75, T47D) were sensitive to $\omega-3$ LC-PUFAs. AA was not tested. In general, these studies concluded that PUFAs or $\omega-3$ PUFAs inhibit cell proliferation through 
the formation of lipid hydroperoxides. However, the careful re-examination of key publications by Diggle (2002) shows that the control cells used in these studies were not valid (e.g. fibroblast vs epithelial cells). Also, the cytotoxic/anti-proliferative effects induced by both $\omega-3$ and $\omega-6$ PUFAs on different cell types, and associated with an increase in lipid peroxidation, cannot account for the in vivo data. This suggests that interaction of PUFAs or their metabolites with signalling pathways could explain their in vivo effects.

\section{III - 3 Conclusion on cells}

Whatever the field of research, cardiac or breast cancer, the in vitro experiments on isolated cells underline the problem of the model used. In the cardiac field, the cells which have been used to reproduce in vivo experiments are rat neonatal cells. There was, to our knowledge, no attempt to use an ischaemia-reperfusion model of isolated cells as the one described by Maddaford et al. (1999). In the cardiac cultured cell model, the fact that very different ways to produce arrhythmias are all sensitive to micromolar EPA, which is thought to act mainly on membrane proteins, needs a careful examination of the experimental conditions.

At that point, this kind of problems applies to cancer cell line models. Indeed, lipoperoxidation has been proposed as one of the possible mechanism for cytotoxicity. Lipid peroxidation is a free-radical chain reaction that is initiated by reactive oxygen species (ROS). ROS are free radicals as well as non radical species (e.g. hydrogen peroxide and singlet oxygen) generated by electrons which have leaked (as a natural and normal phenomenon) from the mitochondrial electron transport systems. The initial reactive species is the superoxide anion which further forms the highly reactive hydroxyl radical (Brand et al., 2004). These ROS are normally eliminated by antioxidant enzymes and radical-scavenging lipid antioxidant vitamins (such as tocopherols and tocotrienols) or other antioxidant nutrients. However, when these enzymes or vitamins are or become unable to cope with an increased ROS production, radicals can react with the alkyl chain of fatty acyl moiety of membrane phospholipids. This reaction is 
facilitated with the degree of unsaturation of the FA leading to oxidized metabolites and degradation products such as fatty acid hydroperoxides, isoprostanes, malondialdehyde (see for a review Kohen \& Nyska, 2002). This initiates the free-radical chain reaction in the membrane at various localizations (such as plasmalemmal, mitochondrial, nuclear membranes) and can lead to alterations in the functioning of membranes proteins.

How does lipoperoxidation occur in vivo knowing that $\mathrm{pO}_{2}$ in tumours is very low (Runkel et al., 1994)? Moreover, since EPA as free FA reversed arrhythmias induced by many different factors in vitro, while the ethyl ester form, which is less peroxidizable, did not, is peroxidation necessary? Can lipoperoxidation occur in vivo despite antioxidant protection systems? These questions have to be answered before transposing in vivo models to in vitro models. Anyway, the knowledge of some mechanisms involved in the development of the pathology and their regulation by $\omega-3$ LC-PUFAs can help to understand some of the beneficial effects of these PUFAs.

\section{IV - IONIC CHANNELS}

Before reviewing the reported effects of $\omega$-3 LC-PUFAs on ionic channels, we would like to suggest another possible membrane target of these lipids, gap-junctions. These proteins are channels which permit cell-to-cell communication. It is known that there is a gap junctional uncoupling along the course of breast cancer development (Carystinos et al., 2001) and during cardiac ischaemia (De Groot \& Coronel, 2004). In that latter case, the decreased conductance of gap junction is closely related to the occurrence of arrhythmias (De Groot \& Coronel, 2004). Increasing gap junctional intercellular communication in a breast cancer cell line (MCF-7) was associated with a reversal of the cancerous phenotype (Saez et al., 2003). Thus, it is possible that any treatment which would increase gap junctional intercellular communication would be beneficial in preventing breast cancer development and cardiac ischaemia-induced arrhythmias. Up to now, few studies report the effect of $\omega$-3 LC-PUFAs on gap junctions and none of these 
concerned breast cancer or cardiac cells. In a colon cancer cell line, Caco-2, Dommels et al. (2001) found no effect of cell incubation in presence of EPA while alpha-linolenic acid (C18:3n3) reduced gap junctional intercellular communication. In cultured human ombilical vein endothelial cells, Zhang et al. (1999) found that cell incubation with EPA was able to prevent hypoxia/reoxygenation-induced gap junction dysfunction. This effect was mediated through an inhibition of a tyrosine kinase.

The modulation of gap junctions by $\omega$-3 LC-PUFAs on breast cancer and cardiac cells remains an unexplored field of research and thus would be worthy of study.

\section{IV $-1 \omega-3$ LC-PUFA effects on cardiac ionic channels}

Since it has been strongly suggested that $\omega$-3 LC-PUFAs were anti-arrhythmic, two main hypotheses were explored. The first one addresses a possible modulation of ionic channels by LC-PUFA.

In 1995, Kang et al. found that $10 \mu \mathrm{M}$ EPA stabilised the resting membrane potential, increased the threshold to trigger an action potential and prolonged the refractory period 3 -fold. Based on these results, Leaf's group proposed that $\omega$-3 LC-PUFAs exerted these effects through the modulation of ion channels activity. They first studied the voltage-gated sodium current $\left(\mathrm{I}_{\mathrm{Na}}\right)$. They found that it was blocked by micromolar concentrations of LC-PUFAs (Xiao et al., 1995). Latter on, they found that asparagine residue 406 in Nav1.5 may be important for the inhibition of the current (Xiao et al., 2001). Initially, it was proposed that such a blockade of $\mathrm{I}_{\mathrm{Na}}$ was pertinent to the antiarrhythmic actions of $\omega$-3 LC-PUFAs. Meanwhile, the same group found that other currents ( $\left.\mathrm{I}_{\mathrm{TO}}, \mathrm{I}_{\mathrm{CaL}}, \mathrm{I}_{\mathrm{KACh}}, \mathrm{I}_{\mathrm{Cl}, \mathrm{AMPc}}\right)$ were also blocked by micromolar doses of EPA or DHA (Leaf et al., 2002). Such non-specific effects of EPA and DHA challenge the proposal that $\omega-3$ PUFAs interact directly with the ionic channels (Leaf et al., 2002). Membrane tension could be altered by FA incorporation leading to changes in ionic channels activity (Andersen et al., 1995). Whatever molecular effects of LC-PUFAs on ionic channels, it is quite surprising that EPA, 
which blocks $\mathrm{I}_{\mathrm{CaL}}$ (Xiao et al., 1997), does not affect cardiac cell contraction (Kang \& Leaf, 1996). Ferrier et al. (2002) formulated the same remark and explained this apparent discrepancy by the existence of a voltage-sensitive release mechanism (VSRM) of calcium which would be insensitive to $\omega$-3 LC-PUFAs. However, the existence of the VSRM is not generally accepted (Brette et al., 2003). Also, Negretti et al. (2000) found a negative inotropic effect of EPA which they attributed to the blockade of $\mathrm{I}_{\mathrm{CaL}}$. Pepe et al. (1994) reported that $5 \mu \mathrm{M}$ DHA did not affect $\mathrm{I}_{\mathrm{CaL}}$ amplitude or cell contraction. These contradictory results and the non-specific effects of EPA and DHA on ionic channels, led to another hypothesis based on oxidative properties of LCPUFAs. Indeed the double bonds of $\omega$-3 LC-PUFAs render them very sensitive to the oxidative status of the environment. In this context, Judé et al. (2003) showed that the prevention of lipoperoxidation of DHA by vitamin $\mathrm{E}$ in the physiological saline solution counteracts the blocking effect on $\mathrm{I}_{\mathrm{TO}}$ of DHA and of DHA plus $\mathrm{H}_{2} \mathrm{O}_{2}$ (figure 3). These authors came to the conclusion that DHA has no effect on ionic channels. Rather, a product of its peroxidation (physiological or not) is responsible for the effects. Therefore, and since the GISSI trial (1999) clearly showed no additional effect of vitamin E on post-infarction mortality, the systematic use of an antioxidant in the perfusion medium could help to discriminate between specific and nonspecific effects.

In conclusion, the sensitivity of some ionic channels to $\omega-3$ LC-PUFAs might participate in their antiarrhythmic properties. It is plausible that sodium channels are sensitive to $\omega-3$ LCPUFAs since animal experiments (McLennan et al., 1992) and cultured cell experiments (Kang et al., 1995) respectively showed that the fibrillation and action potential threshold were increased by these FA. For other currents such as $\mathrm{I}_{\mathrm{CaL}}$, further experiments are needed.

\section{IV - 2 Ionic channels in breast cancer}

If $\omega$-3 LC-PUFAs can modulate the activity of some ionic channels and be healthy through this pathway, the role of ionic channels has to be defined in breast cancer. 
Since 1994 and the seminal work of Marino et al., there are more and more evidence that increased potassium channels activities are associated with increased proliferation rates in different breast cancer cell lines (Woodfork et al., 1995). The channels involved are ATPsensitive channels (Woodfork et al., 1995), $\mathrm{Ca}^{2+}$-activated channels (Wegman et al., 1991; Ouadid-Ahidouch et al, 2004a,b; Roger et al., 2004b), voltage-activated Kv1.1 channels (Ouadid-Ahidouch et al., 2000) and EAG $\mathrm{K}^{+}$channels (Ouadid-Ahidouch et al., 2001). The mechanisms of action of these channels are unknown but it has been proposed that they act through the changes in membrane potential (Wang et al., 1998). The activation of $\mathrm{K}^{+}$channels allows the G1 to $\mathrm{S}$ cell cycle transition (Strobl et al., 1995). Such a hypothesis has been developed after it was observed that the normal proliferation of $\mathrm{T}$ lymphocyte was regulated by the Kv1.3 channel activity (Chandy et al., 1984).

Recently, it has been observed in tumour biopsies that about $50 \%$ of breast cancers were associated with the expression of Task-3, a double-pore domain $\mathrm{K}^{+}$channel (Mu et al., 2003). The molecular role of this channel is unknown but it has been shown to confer a resistance to hypoxia and serum deprivation on cancerous cells.

All these channels are expressed in various normal tissues where they play roles which are not necessarily involved in cell proliferation, such as presynaptic excitability of glutamatergic synapse for $\mathrm{BK}_{\mathrm{Ca}}$ (Hu et al., 2001), insulin secretion for K,ATP (Petersen \& Dunne, 1989). In these native structures or in expression vectors, these channels have been challenged to different fatty acids. Some of them are sensitive to different kinds of PUFAs. For example, the Kv1.1 which has been reported to participate in cancer cell proliferation (OuadidAhidouch et al., 2000), has recently been found to be tightly regulated by AA and $\mathrm{PIP}_{2}$ (a phospholipid rich in LC-PUFAs) (Oliver et al., 2004). K,ATP, the first potassium channels described as being involved in breast cancer cells proliferation (Woodfork et al., 1995) are activated by AA through the production of prostanoids in rat aorta (Engler et al., 2000). Since dietary $\omega$-3 LC-PUFAs substitute for AA in membrane phospholipids, it can be hypothesised 
that $\omega$-3 LC-PUFAs reduce available AA, therefore indirectly reducing K,ATP activity in cancerous cells. In turn, this would reduce cell proliferation.

$\mathrm{BK}_{\mathrm{Ca}}$ also is known to be regulated by unsaturated fatty acids. These effects can be indirect (sensitivity of the channel to metabolites such as prostanoids or through modulation of intracellular calcium homeostasis) but it has also been proposed that these effects can be direct. Denson et al. (2000) compared the effects of different FAs on $\mathrm{BK}_{\mathrm{Ca}}$ channels of pituitary adenoma cells (GH3). They found that $\mathrm{I}_{\mathrm{BKCa}}$ is increased proportionally to the number of double bonds of the FA. The authors proposed that there is a direct interaction between the FA and the channel protein on the cytosolic surface of the membrane which alters the $\mathrm{Ca}^{2+}$ sensitivity of the channel. However, such an effect on breast cancer cells would increase proliferation according to the "membrane potential" hypothesis.

A blockade of EAG channels has been shown to reduce cell proliferation (OuadidAhidouch et al., 2001). Conversely, blockade of hERG channel, the cardiac homologue of EAG, leads to arrhythmias (see Champeroux et al., 2000). Also, inhibition of Task-3 channels in breast cancer cells inhibits proliferation (Pei et al., 2003) but the activation of Trek-1, another doublepore domain protein channel, is antiarrhythmic (Aimond et al., 2000; Judé et al., 2003). Thus, it is unlikely that $\omega$-3 LC-PUFAs exert their beneficial effects through these targets.

\section{IV - 3 Comparison of cardiac and breast cancer cell ionic channels}

If we compare the role of ionic channels, and their sensitivity to $\omega$-3 LC-PUFAs, in breast cancer cell proliferation and cardiac arrhythmias, there is no obvious candidate which could participate in the beneficial effect of these FA. It even seems that, according to their sensitivity to $\omega$-3 LC-PUFAs, their roles are antagonistic with regard to protection.

The involvement of ionic channels in invasion of basement membrane by cultured cells, another aspect of cancer which reflects the beginning of the metastatic process, has been less explored. This is of great importance since mortality is related to the development of metastases. 
It has been shown that the loss of a $\mathrm{Ca}^{2+}$-activated chloride channel (CLCA2) occurs in some metastatic breast cancers (Gruber \& Pauli, 1999). This channel is thus considered as a tumoursuppressor. More recently, a voltage-gated sodium current has been described in a very invasive breast cancer cell line, MDA-MB-231 (Roger et al., 2003). This current participates in the invasivity through mechanisms which do not seem to involve action potentials. It is blocked by micromolar concentrations of tetrodotoxin (TTX) which designates the protein as TTX-resistant. As suggested initially by Roger et al. (2003), the isoform of the channel is the cardiac Nav1.5 (figure 4). Since it has been reported that a fish diet reduces the occurrence of metastases (Hubard et al., 1998) and that some of the antiarrhythmic effects of EPA and DHA involve an inhibition of the cardiac sodium current (Xiao et al., 2001), it is tempting to speculate that $\omega-3$ LC-PUFAs can block the sodium current in breast cancer cells expressing the protein, avoiding or at least delaying the development of metastases. We thus performed preliminary experiments to evaluate the chronic effects of micromolar doses of DHA on $\mathrm{I}_{\mathrm{Na}}$ in MDA-MB-231 cells. We found a significant reduction of the current amplitude but the results need to be confirmed. It must be underlined that this channel protein is found both in cardiac and breast cancer cells. Its blockade can be beneficial in the treatment of arrhythmias and perhaps in the treatment of some breast cancers (see Roger et al., 2004a). Also, this channel can be regulated by kinases such as LC-PUFAs-regulated PKCs. The link between sodium channels, invasion and ischaemiareperfusion-induced arrhythmias might be the $\mathrm{Na}^{+}-\mathrm{H}^{+}$exchanger. Indeed, it has been shown in a cancer cell line (MCF-7) that a lysophospholipid analog, which inhibits proliferation, reduced the activity of the exchanger leading to cytoplasmic acidification (Besson et al., 1996). Likewise, it has been proposed that EPA and DHA inhibit the $\mathrm{Na}^{+}-\mathrm{H}^{+}$exchanger which could account for their cardioprotective effects (Goel et al., 2002).

\section{V - PROTEIN KINASES C}

The regulation of PKCs by different factors like phosphatidylserine (PS), $\mathrm{Ca}^{2+}$, 
DiAcylGlycerol (DAG) is well known. The PKCs are presently divided into three sub-families based on the homology in the regulatory domain and their activating ligands. The classical PKC (cPKC) isozymes $(\alpha, \beta \mathrm{I}, \beta \mathrm{II}, \gamma)$ are activated by the second messengers $\mathrm{Ca}^{2+}$ and DAG in the presence of PS. The novel PKCs $(\mathrm{nPKC})(\delta, \varepsilon, \eta, \theta)$ are activated by DAG in the presence of PS but are insensitive to $\mathrm{Ca}^{2+}$. Both types of PKCs are activated by the tumour-promoting phorbol ester PMA. The third sub-family, the atypical PKCs (aPKCs) $(\zeta, \imath, \lambda, \mu)$ are not activated by PMA, DAG or $\mathrm{Ca}^{2+}$. Each PKC isozyme localises to unique subcellular sites upon stimulation of cardiac myocytes. This suggests that the various PKC isozymes mediate unique functions (Mackay \& Mochly-Rosen, 2001). Also, taking as example one specific target of PKCs, the cardiac calcium channel $\mathrm{Ca}_{\vee} 1.2$, different PKC isozymes were shown to regulate its function depending on its cellular location: channels in T-tubules may be regulated by $\mathrm{PKC}_{\varepsilon}$ while channels in the plasma membrane may be regulated by $\mathrm{PKC}_{\beta I I}$ (see Dorn \& Mochly-Rosen, 2002).

In a pioneer work, Bordoni et al. (1991) suggested that the fatty acid composition of the DAG produced by the $\alpha_{1}$-stimulated phosphoinositide breakdown influences the pattern of activation of protein kinase C. More recently, Madani et al. (2001) showed that the PUFA composition of the DAG is responsible for a differential activation of different isoforms of PKCs, namely $\mathrm{PKC}_{\alpha}, \mathrm{PKC}_{\delta}$ and $\mathrm{PKC}_{\beta \mathrm{I}}$.

Knowing that PKCs are involved in both breast cancer and ischaemia-induced arrhythmias, it is of great interest to compare the mechanisms in both diseases to highlight the possible common features.

\section{V-1 Involvement of PKCs in ischaemia-induced arrhythmias}

Since 1990, it is known that $\alpha_{1}$-adrenoceptors are implicated in myocardial ischaemic damage (Corr et al., 1990). Early after, since ischaemia-reperfusion is associated with increased levels in myocardial $\mathrm{IP}_{3}$, Du et al. (1995) modulated the level of $\mathrm{IP}_{3}$ during reperfusion with blockers such 
as gentamicin or prazosin and found a close correlation between the release of $\mathrm{IP}_{3}$ and arrhythmias occurring after reperfusion. These works initiated numerous studies on the effect of PUFA supplementation on ischaemia-reperfusion-induced $\mathrm{IP}_{3}$ release.

Woodcock et al. (1995) showed that supplementing diet for 8 weeks with oils enriched with $\omega$-3 LC-PUFAs reduced noradrenaline-stimulated $\mathrm{IP}_{3}$ release. They concluded that individual inositol phosphate isomers can affect the inositides metabolism. Soon after, the same group showed that in rats fed fish-oil-supplemented diet, the incorporation of $\omega$-3 LC-PUFAs into cardiac membrane phospholipids was associated with a significant reduction of reperfusioninduced rise in $\mathrm{IP}_{3}$ and arrhythmias as compared to a control group of rats fed $\omega-6$ LC-PUFAs or saturated fatty acids. For these authors, the inhibition of reperfusion-induced rises in $\mathrm{IP}_{3}$ by $\omega-3$ LC-PUFAs after fish oil supplementation provided a possible mechanism for the inhibitory effect of $\omega$-3 LC-PUFAs on reperfusion-induced arrhythmias. Similarly, Nair et al. (2000) showed that in pigs fed diets supplemented with fish oil, stimulated cardiac cells had lower levels of $\mathrm{IP}_{3}$ compared to those isolated from pigs fed diets supplemented with beef tallow. This is of interest since the physiology of pig heart is comparable to that of human heart.

In accordance with the previous results, Reithmann et al. (1996) found similar results in cultured neonatal rat cardiomyocytes incubated for 3 days in presence of $60 \mu \mathrm{M}$ DHA. The reduced release of $\mathrm{IP}_{3}$ was not due to reduced density of $\alpha_{1}$-receptors or reduced concentration of $\mathrm{PIP}_{2}$.

If $\mathrm{IP}_{3}$ metabolism is altered during ischaemia, it is very likely that $\mathrm{PKC}$ activity is also changed in such a situation. Indeed, Strasser et al. (1999) showed that PKC activity was increased in ischaemic rat heart. More precisely, they showed that acute (1 minute) ischaemia led to the translocation of $\mathrm{PKC}_{\alpha}, \mathrm{PKC}_{\delta}, \mathrm{PKC}_{\varepsilon}$ and $\mathrm{PKC}_{\zeta}$ isoforms to the particulate fraction and that prolonged ischaemia (60 minutes) increased total PKC activity associated with isozyme-specific induction of $\mathrm{PKC}_{\delta}$ and $\mathrm{PKC}_{\varepsilon}$. Later on, Tölg et al. (2001) showed that activation of PKCs is necessary to observe ischaemia-induced arrhythmogenesis. They did not test for the involvement 
of specific $\mathrm{PKC}$ isoforms, especially $\mathrm{PKC}_{\delta}$ and $\mathrm{PKC}_{\varepsilon} . \mathrm{PKC}_{\delta}$ is thought to be deleterious while $\mathrm{PKC}_{\varepsilon}$ has been shown to exert beneficial effects particularly in the preconditioning phenomenon. Preconditioning describes the fact that short periods of ischaemia just prior to prolonged ischaemia reduce cardiac damage by prolonged ischaemia in vivo and in vitro (Cohen et al., 2000). Since the activation of $\mathrm{PKC}_{\varepsilon}$ participates in this phenomenon, it can be proposed that $\mathrm{PKC}_{\varepsilon}$ activation by $\omega-3$ LC-PUFA could participate in their cardioprotective effects.

\section{$V-2$ Involvement of PKCs in breast cancer}

The involvement of PKCs in the development of breast cancer has been suggested a long time ago and PKCs have even been proposed to serve as markers of this disease (see MacKay \& Twelves, 2003 for a review). Since then, the involvement of PKCs in mammary carcinogenesis has been extensively studied but did not dramatically increase our knowledge.

PKCs are known to be involved in proliferation, estrogen-sensitivity, apoptosis and metastasis. The involvement of PKCs in such a variety of biological phenomena may be explained in part by the expression of different isoforms in breast tissue and the possibility that each isoform selectively phosphorylates different target proteins which mediate different biological responses (Kiley et al., 1996).

Up to now, the PKCs of interest in breast cancer are $\mathrm{PKC}_{\alpha}$ and $\mathrm{PKC}_{\delta}$ which are recognised to be involved respectively in proliferation (Lahn et al., 2004) and metastasis (see Debies \& Welsh, 2002). In both cases, the fact that these PKCs are upregulated led to develop specific isoform inhibitors which are presently tested in clinical trials (see MacKay \& Twelves, 2003; Lahn et al., 2004).

The signalisation pathways have been described in the other above-cited reviews and are out of the scope of the present one. The important point is to underline that $\mathrm{PKC}_{\alpha}$ and $\mathrm{PKC}_{\delta}$ are both probably involved in some oncogenic signalisation pathway. 


\section{$V-3$ Comparison of the role of PKCs in breast cancer and heart}

To conclude on the role of PKCs in ischaemia-induced arrhythmias and in breast cancers, we can say that in both cases, these kinases are up-regulated. Interestingly, some isoforms are involved in different aspects of both diseases. $\mathrm{PKC}_{\alpha}$ is activated in the early phase of cardiac ischaemia and is involved in breast cancer cell proliferation. $\mathrm{PKC}_{\delta}$ is activated in chronic ischaemia phase (see also Chen et al., 2001) and is involved in metastasis. These isoforms are good candidates to the modulation of their activity by different molecular species of DAG as shown by Madani et al. (2001). It is thus reasonable to propose that the sensitivity of $\mathrm{PKC}_{\alpha}$ and $\mathrm{PKC}_{\delta}$ to the $\mathrm{FA}$ composition of DAG participates in $\omega-3$ LC-PUFAs beneficial properties on breast cancers and CHD.

\section{VI - CALCIUM HOMEOSTASIS}

$\mathrm{Ca}^{2+}$ is a second messenger which is finely regulated. However, it has also been shown that, in physiopathological situations, it is involved in the genesis of arrhythmias and in the control of cell proliferation. As such, it is of interest to see how $\omega-3$ LC-PUFAs interfere with the $\mathrm{Ca}^{2+}$ homeostasis of cardiac and breast cancer cells.

\section{VI-1 Calcium and $\omega-3$ LC-PUFAs in cardiac cells}

In 1993, Taffet et al. have shown that feeding rats an $\omega$-3 LC-PUFAs diet increased the incorporation of DHA, at the expense of AA, in sarcoplasmic reticulum (SR) phospholipids. This effect was associated with a lower $\mathrm{Ca}^{2+}$ loading of the SR and a decreased activity of the SR $\mathrm{Ca}^{2+}$-ATPases. Later, Xiao et al. (1997) found that EPA, which inhibits $\mathrm{I}_{\mathrm{CaL}}$ in rat cardiomyocytes, reduced the amplitude of the calcium transient. This effect was attributed to the decreased amplitude of $\mathrm{I}_{\mathrm{CaL}}$ since the characteristics of $\mathrm{Ca}^{2+}$ sparks were not changed. This suggested a lack of effect on RYR2, the SR calcium channel. In the same type of cells, Negretti et al. (2000) found a decreased resting calcium concentration associated with lower spontaneous 
SR releases of $\mathrm{Ca}^{2+}$. This might be attributed to a reduced entry of $\mathrm{Ca}^{2+}$ through the calcium channels but it does not explain the increase in SR calcium load (Negretti et al., 2000). The authors explained the phenomenon by an inhibition of the release mechanism, possibly on RYR2. The decreased resting intracellular calcium concentration is rather difficult to reconcile with the slower relaxation of the calcium transient in cells from rat fed $\omega$-3 LC-PUFAs (Leifert et al., 2001). This later result is however compatible with the recent inhibition of the $\mathrm{Na}-\mathrm{Ca}$ exchanger found by Xiao et al. (2004).

In summary, the results are contradictory at the molecular level. But all studies showed that the calcium homeostasis is modified in cells perfused with PUFAs and in rats fed fish oil. The modifications observed are in agreement with an antiarrhythmic effect of $\omega-3$ LC-PUFAs. Indeed, increases in cytoplasmic $\mathrm{Ca}^{2+}$ levels, and sensitisation of $\mathrm{RYR} 2$ to $\mathrm{Ca}^{2+}$ are both associated with spontaneous $\mathrm{Ca}^{2+}$ release which, through the initiation of an inward $\mathrm{I}_{\mathrm{NaCa}}$, can trigger extrasystoles. These spontaneous contractions, typical of isolated rat cells, are inhibited by $\omega-3$ LC-PUFAs.

\section{VI-2 Calcium and $\omega-3$ LC-PUFAs in mammary epithelial cancer cells}

In human mammary epithelial cells, the homeostasis of $\mathrm{Ca}^{2+}$ is of importance for cells but the regulations are very different from those in cardiac cells. The intracellular stores of calcium (endoplasmic reticulum, ER) can release calcium mainly following the $\mathrm{IP}_{3}$ increase $\left(\mathrm{IP}_{3}\right.$-induced calcium release, Patel \& Schrey, 1992) while in heart cells the calcium release is induced by the elevation of cytoplasmic $\mathrm{Ca}^{2+}\left(\mathrm{Ca}^{2+}\right.$-induced calcium release, Fabiato, 1985). The release of $\mathrm{Ca}^{2+}$ can occur thanks to the activity of a thapsigargine-sensitive $\mathrm{Ca}^{2+}$-ATPase responsible for the loading of the store (Serguev \& Rhoten, 1998). In a study, performed on BT-20 cells, Serguev \& Rhoten suggested the existence of voltage-insensitive $\mathrm{Ca}^{2+}$ channels but did not find the evidence of capacitive $\mathrm{Ca}^{2+}$ entry. 
The physiological role of intracellular calcium seems to rely mainly on transcription, enzyme activation and regulation of apoptosis but the precise pathways are not known. However, an increase in intracellular calcium is clearly associated with an increased proliferation (Tannheimer et al., 1997; Roger et al., 2004b). This increased proliferation might be consecutive to the MAPK activation as shown in MCF-7 cells (Improto-Brears et al., 1999). Conversely, hormones like 1,25(OH)2D3 which inhibit breast tumour growth, induce the emptying of intracellular $\mathrm{Ca}^{2+}$ pools and increase apoptosis (Vandewalle et al., 1995). EPA also has been shown to inhibit capacitive calcium influx in different cancer cell lines (e.g. cervix, liver, glioblastoma, breast), leading to the emptying of the ER (Palakurthi et al., 2000). This effect, which was antagonized by vitamin E, suggesting the involvement of peroxidation, was associated to a reduced proliferation.

\section{VI-3 Conclusion on calcium and $\omega-3$ LC-PUFAs}

In both kinds of cells, calcium is important to their physiology. Increased cytosolic $\mathrm{Ca}^{2+}$ is arrhythmogenic in cardiac cells and filling of the ER with $\mathrm{Ca}^{2+}$ enhances proliferation in mammary epithelial cells. An apparent beneficial effect of $\omega-3$ LC-PUFAs has been reported but at the molecular level, contradictory results were obtained. To simplify the role of $\mathrm{Ca}^{2+}$, increasing cytosolic $\mathrm{Ca}^{2+}$ concentration is deleterious and any attempt to reduce it, e.g. with $\omega-3$ LC-PUFAs, might be beneficial.

The results published by Palakurthi et al. (2000) on cancer cells underline the role of peroxidation. Lipoperoxidation cannot be avoided if antioxidants are not used. Therefore, experiments studying the effects of $\omega$-3 LC-PUFAs should be performed in controlled redox conditions.

\section{VII - MATRIX METALLOPROTEINASES}

Matrix metalloproteinases (MMPs) are enzymes which are implicated in physiological 
(wound healing, angiogenesis, development, etc.) and physiopathological processes such as cancer and myocardial infarction. These proteases can be modulated by $\omega-3$ LC-PUFAs.

Very recent reviews describe the regulation of MMPs and their involvement in diseases (Egeblad \& Werb, 2002; Bartsch et al., 2003; Jones et al., 2003; Lindsey, 2004) and we will only give a rapid overview of MMPs. MMPs are a family of zinc-dependent endopeptidases capable of cleaving extracellular matrix components. They comprise more than 25 individual members divided into specific classes based on in vitro substrate specificity for various extracellular matrix components: collagenases (MMP1, MMP8, MMP13), gelatinases (MMP2, MMP9), stromelysines (MMP3, MMP7, MMP10, MMP11), metalloelastases ((MMP12) and membranetype matrix metalloproteinases (MMP14, MMP15, MMP16, MMP17, MMP24, MMP25). MMPs are regulated at multiple levels such as transcription, translation, secretion and their activation, which requires calcium, is rather complex (see Egeblad \& Werb, 2002; Jones et al., 2003 for details). It is important to notice the existence of tissue-specific inhibitors of metalloproteinases (TIMP-1, TIMP-2, TIMP-3 and TIMP-4).

\section{VII - 1 MMPs in heart diseases}

Activation of MMPs has been shown to occur following myocardial infarction (MI). They are involved in ventricles remodelling leading to heart failure, as well as in neovascularisation. While different MMPs and TIMPs are regulated following long term remodelling, which is out of the scope of the present paper, it however seems that MMP9 and TIMP-1 are upregulated in the hours following MI (see Jones et al., 2003 for review). Blankenberg et al. (2003) found that plasma levels of MMP9 were closely correlated to mortality in patients with CHD. But, since TIMP-1 is also elevated following acute coronary syndrome, it is more important to measure MMPs activities than their levels. 


\section{VII - 2 MMPs in breast cancers}

The expression and activation of MMPs is increased in almost all human cancers compared with normal tissue. They are implicated in migration, invasion, metastasis and tumour angiogenesis. Thus, they are potential targets for therapies (Egleblad \& Werb, 2002).

It is generally admitted that MMPs are produced by tumour stromal cells such as fibroblasts but Bartsch et al. (2003) found that different MMPs including MMP2 and MMP9 are expressed by some tumour cell lines (the level of expression depending on experimental conditions) but not by a normal breast epithelial cell line.

\section{VII - 3 MMPs and $\omega-3$ LC-PUFAs}

In 1993, Rose \& Connolly found that dietary $\omega$-3 LC-PUFAs inhibited the growth and metastasis of transplanted MDA-MB-435 human breast cancer cells in athymic nude mice. The invasion capacity of the cells, evaluated in vitro, gave similar results when the cells were incubated with EPA and DHA (Connolly \& Rose, 1993). The authors suggested that these effects were mediated through eicosanoid synthesis.

Using similar cancer cell transplantation in nude mice model, Suzuki et al. (1997) showed that the inhibition of lung metastasis of a colon cancer cell line by EPA and DHA was associated with a reduced activity of MMP9 while MMP2 activity was not affected by the presence of these PUFAs in the diet. The effect on metastasis was negatively correlated to the concentration of AA in the tumour tissue. Such a reduction in MMP9 activity was found by Harris et al. (2001) in uterus, placenta and liver tissues of rat fed diets enriched with DHA. They also found a decreased activity of MMP2. They explained their finding by a competition of the $\omega-3$ LCPUFAs with AA for incorporation into membrane phospholipids. This would consequently change the production of prostaglandin $\mathrm{PGE}_{2}$ (an AA metabolite produced by cyclooxygenase) and affect MMP activities. 
In the cardiac field, the only study we are aware of describes that EPA inhibits hypoxiareoxygenation-induced lactate deshydrogenase release, a marker of cardiac injury (Chen et al., 2003). They found, on isolated rat cardiac cells, that the beneficial effects of EPA were associated with a reduced expression and activity of MMP-1. They observed that lipid peroxidation was reduced in EPA treated cells and inferred that peroxidation was a key factor. They did not evaluate the activities of other MMPs.

It thus seems that MMPs are involved in both breast cancers and CHD. The situation is very complex owing to the number of MMPs and the regulation of their expression and activity. The activity of MMP2 and MMP9 is increased in both pathologies and can be reduced by $\omega-3$ LCPUFAs. This makes them possible candidates to explain the beneficial effects of fish oil, either directly or indirectly through other PUFAs-sensitive regulators (e.g. $\left.\mathrm{Ca}^{2+}, \mathrm{PKCs}\right)$.

\section{VIII - GENERAL CONCLUSION}

To conclude, we can say that $\omega$-3 LC-PUFAs can act at very different levels of the cellular physiology (see figure 5). Some of the sensitive pathways are cell-type specific but others are shared. On this base, we think that the comparison of the cellular effects of $\omega-3$ LC-PUFAs on cardiac cells and breast cancer cells can help to better understand some of their mechanisms of action. Recent reviews describe possible specific targets of $\omega-3$ LC-PUFAs in heart (Das, 2000) and cancers (Siddiqui et al., 2004).

What is the plasma level of $\omega-3$ LC-PUFAs? It is difficult to answer this question since there are no attempts, to our knowledge, to quantify precisely these PUFAs in different dietary conditions. In their study on rat cardiac cells, Negretti et al. (2000) estimated the free fatty acid concentration in the plasma to be between 8 and $32 \mu \mathrm{M}$.

One difficulty in understanding the molecular effects of $\omega-3$ LC-PUFAs relies on the quality of the models. While the pathological situation in which beneficial effects of $\omega$-3 LC-PUFAs are observed is well defined in the heart (CHD), no study used a corresponding model at the cellular 
level. Breast cancers have multifactorial etiologies and the conditions in which the effects of $\omega-3$ LC-PUFAs are beneficial are far to be delineated. Another difficulty which appears when studying cancer, is to identify what is linked to the cancer phenotype and what is not, because few comparisons are made with non-cancerous cells (Diggle, 2002). For example, more and more publications report the expression of ionic channels in cancer cells but their role in pathological proliferation and invasion is not clearly linked to the cancer phenotype. This might be due to the fact that few of them challenge normal cells.

PKCs are among the best candidates as targets of $\omega-3$ LC-PUFAs. The PKCs of interest seem to be $\mathrm{PKC}_{\alpha}$ and $\mathrm{PKC}_{\delta}$ but we cannot exclude that other PKCs are also involved. At that point of the discussion it must be underlined that experiments generally focus and observe a change in various activities $\left(\mathrm{Ca}^{2+}, \mathrm{PKCs}\right.$, ionic channels, MMPs) but some of them are linked. For example, $\mathrm{PKC}_{\alpha}$ is upregulated in some breast cancers. Depletion in intracellular $\mathrm{Ca}^{2+}$ stores is associated to reduced proliferation thus, since $\mathrm{PKC}_{\alpha}$ is $\mathrm{Ca}^{2+}$ dependent, we can imagine that its activity would be decreased in presence of EPA or DHA because of the reduction of cytosolic calcium.

One major concern remaining in these studies is the very nature of the molecules (FA or derivatives) which actually exert the $\omega-3$ LC-PUFAs beneficial effects. Is lipid peroxidation a result of uncontrolled experimental conditions? Does peroxidation occur to the same extent in situ as it does in cellular models? Do the lipids need to be first peroxidized in order to be active? These points are of great importance to better understand the effects of $\omega$-3 LC-PUFAs on health. 


\section{REFERENCES}

Aimond, F., Rauzier, J.-M., Bony, C., Vassort, G., 2000.Simultaneous activation of p38 MAPK and p42/44 MAPK by ATP stimulates the $\mathrm{K}^{+}$current $\mathrm{I}_{\mathrm{TREK}}$ in cardiomyocytes. J. Biol. Chem., 275, 39110-39116.

Andersen, O., Nielsen, C., Maer, A., Lundbaek, J., Goulian, M., Koeppe II R., 1995. Ion channels as tools to monitor lipid bilayer-membrane protein interactions: gramicidin channels as molecular force transducers. Methods Enzymol., 294, 208-224.

Bagga, D., Wang, L., Farias-Eisner, R., Glaspy, J., Reddy, S., 2003. Differential effects of prostaglandin derived from $\omega-6$ and $\omega-3$ polyunsaturated fatty acids on COX-2 expression and IL-6 secretion. Proc. Natl. Acad. Sci. USA, 100, 1751-1756.

Bang, H., Dyerberg, J., Hjoorne, N., 1976. The composition of food consumed by Greenland Eskimos. Acta Med. Scand., 200 (1-2), 69-73.

Bartsch, J., Staren, E., Appert, H., 2003. Matrix metalloproteinases expression in breast cancer. J. Surg. Res., 110, 383-392.

Besson, P., Gore, J., Vincent, E., Hoinard, C., Bougnoux, P., 1996. Inhibition of Na+/H+ exchanger activity by an alkyl-lysophospholipid analogue in a human breast cancer cell line. Biochem. Pharmacol., 51(9), 1153-1158.

Billman, G., Kang, J., Leaf, A., 1999. Prevention of ischemia-induced cardiac suddent death by pure n-3 polyunsaturated fatty acids. Circulation, 99, 2452-2457.

Blankenberg, S., Rupprecht, H., Poirier, O., Bickel, C., Smieja, M., Hafner, G., Meyer, J., Cambien, F., Tiret, L., AtheroGene Investigators, 2003. Plasma concentrations and genetic variation of matrix metalloproteinase 9 and prognosis of patients with cardiovascular disease. Circulation, 107(12), 1579-1585. 
Bordoni, A., Biagi, P., Rossi, C., Hrelia, S., 1991. Alpha-1-stimulated phosphoinositide breakdown in cultured cardiomyocytes: diacylglycerol production and composition in docosahexaenoic acid supplemented cells. Biochem. Biophys. Res. Comm., 174, 869-877.

Bougnoux, P., 1999. N-3 polyunsaturated fatty acids and cancer. Curr. Op. Clin. Nutr. Metab. Care, 2, 121-126.

Brand, M., Affourtit, C., Esteves, T., Green, K., Lambert, A., Miwa, S., Pakay, J., Parker, N. 2004. Mitochondrial superoxide: production, biological effects, and activation of uncoupling proteins. Free Radic Biol Med. 37(6), 755-767.

Brette, F., Le Guennec, J.-Y., Findlay, I., 2003. Low-voltage triggering of calcium release from the sarcoplasmic reticulum in cardiac muscle cells. Am. J. Physiol. Cell Physiol., 285(6), C1544C1552.

Buell, P., 1973. Changing incidence of breast cancer in Japanese-American women. J. Natl. Cancer Inst., 51(5), 1479-1483.

Burr, M., Fehily, A., Gilbert, J., Rogers, S., Holliday, R., Sweetnam, P., Elwood, P., Deadman, M., 1989. Effects of changes in fat, fish, and fibre intakes on death and myocardial reinfarction: Diet and Reinfarction Trial (DART). Lancet, 334, 757-761.

Carystinos, G., Bier, A., Batist, G., 2001. The role of connexin-mediated cell-cell communication in breaast cancer metastasis. J. Mammary Gland. Biol. Neoplasia., 6(4), 431-440.

Chajes, V., Bougnoux, P., 2003. Omega-6/omega-3 polyunsaturated fatty acid ratio and cancer. World Rev Nutr Diet, 92, 133-151.

Chajès, V., Sattler, W., Stranzl, A., Kostner, G., 1995. Influence of fatty acids on the growth of human breast cancer cells in vitro: relationship to peroxides and vitamin E. Breast Cancer res. Treat., 34(3), 199-212.

Champeroux, P., Martel, E., Vannier, C., Blanc, V., Le Guennec J.-Y., Fowler, J., Richard, S., 2000. The preclinical assessment for the risk for QT interval prolongation. Therapie, 55,101-109. 
Chandy, K., DeCoursey, T., Cahalan, M., McLaughlin, C., Gupta, S., 1984. Voltage-gated potassium channels are required for human T lymphocyte activation. J Exp Med., 160(2), 369385.

Chen, L., Hahn, H., Wu, G., Chen, C-H., Liron, T., Schechtman, D., Cavallaro, G., Banci, L., Guo, Y., Bolli, R., Dorn, G., Mochly-Rosen, D., 2001. Opposing cardioprotective actions and parallel hypertrophic effects of ${ }_{\alpha}$ PKC and ${ }_{\delta}$ PKC. Proc. Natl. Acad. Sci. USA, 98, 11114-11119.

Chen, H., Li, D., Roberts, G., Saldeen, T., Mehta, J., 2003. Eicosapentaenoic acid inhibits hypoxiareoxygenation-induced injury by attenuating upregulation of MMP-1 in adult rat myocytes. Cardiovasc. Res., 59, 7-13.

Cohen, L., Chen-Backlund, J., Sepkovic, D., Sugie, S., 1993. Effect of varying proportions of dietary menhaden and corn oil on experimental rat mammary tumour promotion. Lipids, 28(5), 449-456.

Cohen, M., Baines, C., Downey, J., 2000. Ischemic preconditioning: from adenosine receptor of $\mathrm{K}_{\text {ATP }}$ channel. Annu. Rev. Physiol., 62, 79-109.

Connolly, J., Rose, D., 1993. Effects of fatty acids on invasion through reconstituted basement membrane ('Matrigel') by a human breast cancer cell line. Cancer Lett., 75, 137-142.

Corr, P., Yamada, K., Torre, S., 1990. Modulation of $\alpha$-adrenergic receptors and their coupling in ischemic heart. Basic Res. Cardiol., 85, 31-45.

Das, U., 2000. Beneficial effect(s) of n-3 fatty acids in cardiovascular diseases: but, why and how ? Prostaglandins Leukot. Essent. Fatty Acids, 63(6), 351-362.

Debbies, M., Welch, D., 2002. Genetic basis of human breast cancer metastasis. J. Mammary Gland Biol., 6, 441-451.

De Groot, J., Coronel, R., 2004. Acute ischemia-induced gap junctional uncoupling and arrhythmogenesis. Cardiovasc. Res., 62(2), 323-334.

Denson, D., Wang, X., Worrell, R., Eaton, D., 2000. Effects of fatty acids on BK channels in GH3 cells. Am. J. Physiol. Cell. Physiol., 279, C1211-C1219. 
Diggle, C., 2002. In vitro studies on the relationship between polyunsaturated fatty acids and cancer: tumour or tissue specific effects ? Progress Lipid Res., 41, 240-253.

Dommels, Y., Alink, G., Linssen, J., Van Ommen, B., 2002. Effects of n-3 and n-3 polyunsaturated fatty acids on gap junctional intercellular communication during spontaneous differentiation of the human colon adenocarcinoma cell line Caco-2. Nutr. Cancer., 42(1), 125-130.

Dorn, G., Mochly-Rosen,, D., 2002. Intracellular transport mechanisms of signal transducers. Annu. Rev. Physiol., 64, 407-429.

Du, X., Anderson, K., Jacobsen, A., Woodcock, E., Dart, A., 1995. Suppression of ventricular arrhythmias during ischaemia-reperfusion by agents inhibiting Ins(1,4,5)P3 release. Circulation, $91,2712-2716$.

Egeblad, M., Werb, Z., 2002. New functions for the matrix matalloproteinases in cancer progression. Nat. Rev. Cancer, 2, 161-174.

Engler, M., Engler, M., Browne, A., Sun, Y., Sievers, R., 2000. Mechanisms of vasorelaxation induced by eicosapentaenoic acid (20:5n-3) in WKY rat aorta. Br. J. Pharmacol., 131, 17931799.

Fabiato, A., 1985. Simulated calcium current can both cause calcium loading in and trigger calcium release from the sarcoplasmic reticulum of a skinned canine cardiac Purkinje cell. J. Gen. Physiol., 85, 291-320.

Fay, M., Freedman, L., Clifford, C., Midthune, D., 1997. Effect of different types and amounts of fat on the development of mammary tumours in rodents: a review. Cancer Res., 57, 1379-1388.

Ferrier, G., Redondo, I., Zhu, J., Murphy, M., 2002. Differential effects of docosahexaenoic acid on contractions and L-type $\mathrm{Ca}^{2+}$ current in adult cardiac myocytes. Cardiovasc. Res., 54, 601-610.

Globocan. World cancer report, 2000. Stewart, B., Kleihues, P., (Eds). IARC Press. Lyon (France).

GISSI-Prevenzione Investigators, 1999. Dietary supplementation with n-3 polyunsaturated fatty acids and vitamin E after myocardial infarction: results of the GISSI-Prevenzione trial. Lancet, $354,447-455$. 
Goel, D., Maddaford, T., Pierce, G., 2002. Effects of $\omega-3$ polyunsaturated fatty acids on cardiac sarcolemmal Na ${ }^{+} / \mathrm{H}+$ exchange. Am. J. Physiol. Heart, 283, H1688-H1694.

Grammatikos, S., Subbaiah, P., Victor, T., Miller, W., 1994. N-3 and n-6 fatty acid processing and growth effects in neoplastic and non-cancerous human mammary epithelial cell lines. Br. J. Cancer, 70(2), 219-227.

Gruber, A., Pauli, B., 1999. Tumorogenicity of human breast cancer is associated with loss of the $\mathrm{Ca}^{2+}$-activated chloride channel CLCA2. Cancer Res., 59, 5488-5491.

Harris, M., Hansen, R., Vidsuhiphan, P., Koslo, J., Thomas, J., Watkins, B., Allen, K., 2001. Effects of conjugated linoleic acids and docosahexaenoic acid on rat liver and preorductive tissue fatty acids, prostaglandins and matrix metalloproteinase production. Prostaglandin Leukot. Essent. Fatty Acids, 65(1), 23-29.

Hu, H., Shao, L.-R., Chavoshy, S., Gu, N., Trieb, M., Behrens, R., Laake, P., Pongs, O., Knaus, H., Ottersen, O., Storm, J., 2001. Presynaptic $\mathrm{Ca}^{2+}$-activated $\mathrm{K}^{+}$channels in glutamatergic hippocampal terminals and their role in spike repolarization and regulation of transmitter release. J. Neurosci., 21, 9585-9597.

Hubard, N., Lim, D., Erickson, K., 1998. Alteration of murine mammary tumorigenesis by dietary enrichment with n-3 fatty acids in fish oil. Cancer Lett., 124,1-7.

Improta-Brears, T., Whorton, A., Codazzi, ., York, J., Meyer, T., McDonnell, D., 1999. Estrogeninduced activation of mitogen-activated protein kinase requires mobilization of intracellular calcium. Proc. Natl. Acd. Sci. USA, 96, 4686-4691.

Jones, C., Sane, D., Herrington, D., 2003. Matrix metalloproteinases: a review of their structural and role in acute coronary syndrome. Cardiovasc. Res., 59, 812-823.

Judé, S., Bedut, S., Roger, S., Pinault, M., Champeroux, P., White, E., Le Guennec, J.-Y., 2003. Peroxidation of docosahexaenoic acid is responsible for its effects on ITO and ISS in rat ventricular myocytes. Br. J. Pharmacol., 139, 816-822. 
Kagawa, Y., Nishizawa, M., Suzuki, M., Miyatake, T., Hamamoto, T., Goto, K., Motonaga, E., Izumikawa, H., Hirata, H., Ebihara, A., 1982. Eicosapolyenoic acids of serum lipids of Japanese islanders with low incidence of cardiovascular diseases. J. Nutr. Sci. Vitaminol., 28, 441-453.

Kang, J., Leaf, A., 1994. Effects of long-chain polyunsaturated fatty acids on the contraction of neonatal rat cardiac myocytes. Proc. Natl. Acad. Sci. USA, 91, 9886-9890.

Kang, J., Leaf, A., 1996. Protective effects of free polyunsaturated fatty acids on arrhythmias induced by lysophosphatidylcholine or palmitoylcarnitine in neonatal rat cardiac myocytes. Eur. J. Pharmacol., 297, 97-106.

Kang, J., Xiao, Y., Leaf, A., 1995. Free long-chain, polyunsaturated fatty acids reduce membrane electrical excitability in neonatal rat cardiac myocytes. Proc. Natl. Acad. Sci. USA, 92, 39974001.

Kiley, S., Welsh, J., Narvaez, C., Jaken, S., 1996. Protein kinase C isozymes and substrates in mammary carcinogenesis. 1, 177-187.

Kohen, R., Nyska, A., 2002. Oxidation of biological systems: oxidative stress phenomena, antioxidants, redox reactions, and methods for their quantification. Toxicol. Pathol., 30(6), 620650.

Kris-Etherton, P., Harris, W., Appel, L., 2002. Fish consumption, fish oil, omega-3 fatty acids, and cardiovascular disease. Circulation, 106, 2747-2757.

Kromhout, D., Bosschieter, E., de Lezenne Coulander, C., 1985. The inverse relation between fish consumption and 20-year mortality from coronary heart disease. N. Engl. J. Med., 312, 12051209.

Lahn, M., Köhler, G., Sundell, K., Su, C., Li, S., Paterson, B., Bumol, T., 2004. Protein kinase alpha expression in breast and ovarian cancer. Oncology, 67, 1-10.

Leaf, A., Kang, J., Xiao, Y., Billman, G., 2003. Clinical prevention of sudden cardiac death by n-3 polyunsaturated fatty acids and mechanism of prevention of arrhythmias by n-3 fish oils. Circulation, 107, 2646-2652. 
Leaf, A., Xiao, Y.-F., Kang, J., 2002. Interactions of n-3 fatty acids with ion channels in excitable tissues. Prostag. Leukotr. Ess., 67 (2-3), 113-120.

Leifert, W., Dorian, C., Jahangiri, A., McMurchie, E., 2001. Dietary fish oil prevents asynchronous contractility and alters $\mathrm{Ca}^{2+}$ handling in adult rat cardiomyocytes. J. Nutri. Biochem., 12, 365376.

Lindsey, M., 2004. MMP induction and inhibition in myocardial infarction. Heart Fail. Rev., 9, 7 19.

Mackay, K., Mochly-Rosen, D., 2001. Localization, anchoring, and functions of protein kinase C isozymes in the heart. J. Mol. Cell. Cardiol., 33, 1301-1307.

Mackay, H., Twelves, C., 2003. Protein kinase C: a target for anticancer drugs ? Endocrine-related cancer, 10, 389-396.

Madani, S., Hichami, H., Legrand, A., Belleville, J., Khan, N., 2001. Implication of acyl chain of diacylglycerols in activation of different isoforms of protein kinase C. FASEB J., 15, 2592-2601.

Maddaford, T., Hurtado, C., Sobrattee, S., Czubryt, M., Pierce, G., 1999. A model of low-flow ischemia and reperfusion in single, beating adult cardiomyocytes. Am. J. Physiol heart, 46, H788-H798

Marchioli, R., Barzi, F., Bomba, E., Chieffo, C., Di Gregorio, D., Di Mascio, R., Franzosi, M., Geraci, E., Levantesi, G., Maggioni, A., Mantini, L., Marfisi, R., Mastrogiuseppe, G., Mininni, N., Nicolosi, G., Santini, M., Schweiger, C., Tavazzi, L., Tognoni, G., Tucci, C., Valagussa, F., GISSI-Prevenzione Investigators, 2002. Early protection against sudden death by n-3 polyunsaturated fatty acids after myocardial infarction: time-course analysis of the results of the Gruppo Italiano per lo Studio della Sopravvivenza nell'Infarto Miocardico (GISSI)-Prevenzione. Circulation, 105, 1897-1903.

Marino, A., Iliev, I., Schwalke, M., Gonzalez, E., Marler, K., Flanagan, C., 1994. Association between cell membrane potential and breast cancer. Tumour Biol., 15(2), 82-9. 
McLennan, P., Abeywardena, M., Charnock, J., 1988. Dietary fish oil prevents ventricular fibrillation following coronary artery occlusion and reperfusion. Am. Heart J., 116, 709-717.

McLennan, P., Bridle, T., Abeywardena, M., Charnock, J., 1992. Dietary lipid modulation of ventricular fibrillation threshold in the marmoset monkey. Am. Heart J., 123, 1555-1561.

McLennan, P., Howe, P., Abeywardena, M., Muggli, R., Raederstorff, D., Mano, M., Rayner, T., Head, R., 1996. The cardiovascular protective role of docosahexaenoic acid. Eur. J. Pharmacol., 300, 83-89.

Mu, D., Chen, L., Zhang, X., See, L., Koch, C., Yen, C., Tong, J., Spiegel, L., Nguyen, K., Servoss, A., Peng, Y., Pei, L., Marks, J., Lowe, S., Hoey, T., Jan, L., McCombie, W., Wigler, M., Powers, S., 2003. Genomic amplification and oncogenic properties of the KCNK9 potassium channel gene. Cancer Cell, 3, 297-302.

Nair, S., Leitch, J., Garg, M., 2000. Suppression of inositol phosphate release by cardiac myocytes isolated from fish oil-fed pigs. Mol. Cell. Biochem., 215, 57-64.

Negretti, N., Pérez, M., Walker, D., O'Neill, S., 2000. Inhibition of sarcoplasmic reticulum function by polyunsaturated fatty acids in intact, isolated myocytes from rat ventricular muscle. J. Physiol., 523.2, 367-375.

Oliver, D., Lien, C.-C., Soom, M., Baukrowitz, T., Jonas, P., Fakler, B., 2004. Functionnal conversion between A-type and delayed rectifier $\mathrm{K}^{+}$channels by membrane lipids. Science, 304 , 265-268.

Ouadid-Ahidouch, H., Chaussade, F., Roudbaraki, M., Slomianny, C., Dewailly, P., Delcourt, P., Prevarskaya, N., 2000. Kv1.1 $\mathrm{K}^{+}$channels identification in human breast carcinoma cells: involvment in cell proliferation. Biochem. Biophys. Res. Comm., 278, 272-277.

Ouadid-Ahidouch, H., Le Bourhis, X., Roudbaraki, M., Toillon, R., Delcourt, P., Prevarskaya, N., 2001. Changes in the $\mathrm{K}^{+}$current density of MCF-7 cells during progression through the cell cycle: possible involvment of a h-ether a gogo $\mathrm{K}^{+}$channel. Recpt. Channels, 7, 345-356. 
Ouadid-Ahidouch, H., Roudbaraki, M., Delcourt, P., Ahidouch, N., Joury, N., Prevarskaya, N., 2004a. Functionnal and molecular identification of intermediate conductance $\mathrm{Ca}^{2+}$-activated $\mathrm{K}^{+}$ channels in breast cancer cells: association with cell cycle progression. Am. J. Physiol., Cell. Physiol., 287, C125-C134.

Ouadid-Ahidouch, H., Roudbaraki, M., Ahidouch, N., Delcourt, P., Prevarskaya, N., 2004b. Cellcycle-dependent expression of the large $\mathrm{Ca}^{2+}$-activated $\mathrm{K}^{+}$channels in breast cancer cells. Biochem. Biophys. Res. Commun., 316, 244-251.

Palakurthi, S., Flückiger, R., Aktas, H., Changolkar, A., Shahsafaei, A., Harneit, S., Kilic, E., Halperin, J., 2000. Inhibition of translation initiation mediates the anticancer effect of the n-3 polyunsaturated fatty acid eicosapentaenoic acid. Cancer Res., 60, 2919-2925.

Patel, K., Schrey, M., 1992. Evidence for a role for protein kinase C in the modulation of bombesinactivated cellular signalling in human breast cancer cells. Mol. Cell. Endocrinol., 85(3), 215-225.

Pei, L, Wiser, O., Slavin, A., Mu, D., Powers, S., Jan, L., Hoey, T,. 2003. Oncogenic potential of TASK3 (KCNK9) depends on K+ channel function. Proc. Natl. A.ad. Sci. USA, 100, 7803-7810.

Pepe, S., Bogdanov, K., Hallaq, H., Spurgeon, H., Leaf, A., Lakatta, E., 1994. $\omega 3$ polyunsaturated fatty acid modulates dihydropyridine effects on L-type $\mathrm{Ca}^{2+}$ channels, cytosolic $\mathrm{Ca}^{2+}$, and contraction in adult rat cardiac myocytes. Proc. Natl. Acad. Sci. USA, 91, 8832-8836.

Petersen, O., Dunne, M., 1989. Regulation of $\mathrm{K}^{+}$channels play a crucial role in the control of insulin secretion. Pflügers Arch., 414, S115-S120.

Reithmann, C., Scheininger, C., Bulgan, T., Werdan, K., 1996. Exposure to the n-3 polyunsaturated fatty acid docosahexaenoic acid impairs $\alpha 1$-adrenoceptor-mediated contractile responses and inositol phosphate formation in rat cardiomyocytes. Naunyn-Schmiedeberg's Arch Pharmcol., $354,109-119$.

Roger, S., Besson, P., Le Guennec, J.-Y., 2003. Involvement of a novel fast inward sodium current in the invasion capacity of a breast cancer cell line. Biochim. Biophys. Acta, 1616, 107-111. 
Roger, S., Le Guennec, J.-Y., Besson, P., 2004a. Particular sensitivity to calcium channel blockers of the fast inward voltage-dependent sodium current involved in the invasive properties of a metastatic breast cancer cell line. Br. J. Pharmacol., 141, 610-615.

Roger, S., Potier, M., Vandier, ., Le Guennec, J.-Y., Besson, P., 2004b. Description and role in proliferation of iberiotoxin-sensitive currents in different human mammary epithelial normal and cancerous cells. Biochim. Biophys. Acta, 1667, 190-199.

Rose, D., Connolly, J., 1993. Effects of dietary omega-3 fatty acids on human breast cancer growth and metastases in nude mice. J. Natl. Cancer Inst., 85, 1743-1747.

Rose, D., Connolly, J., 1999. Omega-3 fatty acids as cancer chemopreventive agents. Pharmacol. Ther., 83, 217-244.

Runkel, S., Wischnik, A., Teubner, J., Kaven, E., Gaa, J., Melchert, F., 1994. Oxygenation of mammary tumors as evaluated by ultrasound-guided computerized-pO2-histography. Adv. Med. Exp. Biol., 345, 351-358.

Saez, C., Velasquez, L., Montoya, M., Eugenin, E., Alvarez, M., 2003. Increased gap junctional intercellular communication is directly related to the anti-tumor effect of all-trans-retinoic acid plus tamoxifen in a human mammary cancer cell line. J. Cell. Biochem., 89(3), 450-461.

Sasaki, T., Kobayashi, Y., Shimizu, J., Wada, M., In'nami, S., Kanke, Y., Takita, T., 1998. Effects of dietary n-3 to n-6 polyunsaturated fatty acid ratio on mammary carcinogenesis in rats. Nutr. Cancer, 30, 137-143.

Senzaki, H., Iwamoto, S., Ogura, E., Kiyozuka, Y., Arita, S., Kurebayashi, J., Takada, H., Hioki, K., Tsubura, A., 1998. Dietary effects of fatty acids on growth and metastasis of KPL-1 human breast cancer cells in vivo and in vitro. Anticancer Res., 18, 1621-1627.

Sergeev, I., Rhoten, W., 1998. Regulation of intracellular calcium in human breast cancer cells. Endocrine, 9(3), 321-327.

Siddiqui, R., Shaikh, S., Sech, L., Yount, H., Stillwell, W., Zaloga, G., 2004. Omega 3-fatty acids: health benefits and cellular mechanisms of action. Med. Chem., 4,859-871. 
Simonsen, N., van't Veer, P., Strain, J., Martin-Moreno, J., Huttunen, J., Navajas, J., Martin, B., Thamm, M., Kardinaal, A., Kok, F., Kohlmeier, L., 1998. Adipose tissue omega-3 and omega-6 fatty acid content and breast cancer in the EURAMIC study. European Community Multicenter Study on Antioxidants, Myocardial Infarction, and Breast Cancer. Am J Epidemiol., 147(4):342352.

Singh, R., Niaz, M., Sharma, J., Kumar, R., Rastogi, V., Moshiri, M. 1997. Randomized, doubleblind, placebo-controlled trial of fish oil and mustard oil in patients with suspected acute myocardial infarction: the Indian experiment of infarct survival-4. Cardiovasc. Drug Ther., 11, 485-491.

Strasser, R., Simonis, G., Schön, S., Braun, M., Ihl-Vahl, R., Weinbrenner, C., Marquetant, R., Kübler, W., 1999. Two distinct mechanisms mediate a differential regulation of protein kinase C isozymes in acute and prolonged myocardial ischemia. Circ. Res., 85, 77-87.

Strobl, J., Wonderlin, W., Flynn, D., 1995. Mitogenic signal transduction in human breast cancer cells. Gen. Pharmacol., 26, 1643-1649.

Suzuki, I., Iigo, M., Ishikawa, C., Kuhara, T., Asamoto, M., Kunimoto, T., Moore, M., Yasawa, K., Araki, E., Tsuda, H., 1997. Inhibitory effects of oleic and docosahexaenoic acids on lung metastasis by colon-carcinoma-26 cells are associated with reduced matrix metalloproteinase-2 and -9 activities. Int. J. Cancer., 73, 607-612.

Taffet, G., Pham, T., Bick, D., Entman, M., Pownall, H., Bick, R., 1993. The calcium uptake of the rat heart sarcoplasmic reticulum is altered by dietary lipid. J. Memb. Biol., 131, 35-42.

Tannheimer, S., Barton, S., Ethier S., Burchiel, S., 1997. Carcinogenic polycyclic aromatic hydrocarbons increase intracellular $\mathrm{Ca}^{2+}$ and cell proliferation in primary human mammary epithelial cells. Carcinogenesis, 18(6), 1177-1182.

Tölg, R., Schreieck, J., Kurz, T., Katus, H., Richardt, G., 2001. Ischaemia-induced ventricular fibrillation in isolated perfused rat heart: role of alpha1A-adrenoceptor mediated activation of protein kinase C. Basic Res. Cardiol., 96, 68-74. 
Vandewalle, B., Hornez, L., Wattez, N., Revillion, F., Lefebvre, J., 1995. Vitamin-D3 derivatives and breast-tumor cell growth: effect on intracellular calcium and apoptosis. Int. J. Cancer, 61(6), 806-811.

Wang, S., Melkoumian, K., Woodfork, C., Cather, A., Davidson, W., Wonderlin, W., Strobl, J., 1998. Evidence for an early G1 ionic event necessary for cell cycle progression and survival in the MCF-7 human breast carcinoma cell line. J. Cell. Physiol., 176, 456-464.

Weber, P., Fischer, S., von Schacky, C., Lorenz, R., Strasser, T., 1986. The conversion of dietary eicosapentaenoic acid to prostaglandins and leukotrienes in man. Prog. Lipid Res., 25, 273-276.

Wegman, E., Young, J., Cook, D., 1991. A 23-pS Ca ${ }^{2+}$-activated $\mathrm{K}^{+}$channel in MCF-7 human breast carcinoma cells: an apparent correlation of channel incidence with the rate of cell proliferation. Pflügers Arch., 417, 562-570.

Willett, W., 1998. Dietary fat intake and cancer risk: a controversial and instructive story. Semin Cancer Biol., 8, 245-253.

Woodcock, E., Anderson, K., Du, X.-J., Dart, A., 1995. Effects of dietary supplementation on inositol phosphate release and metabolism in rat left atria. J. Mol. Cell. Cardiol., 27, 867-871.

Woodfork, K., Wonderlin, V., Peterson, V., Strobl, J., 1995. Inhibition of ATP-sensitive potassium channels causes reversible cell-cycle arrest of human breast cancer cells in tissue culture. J. Cell. Physiol., 162, 163-171.

World Cancer Research Fund, 1997. Food, nutrition and the prevention of cancer : a global perspective. American Institute for Cancer Research, Washington, DC. 670p.

Wynder, E., Rose, D., Cohen, L., 1986. Diet and breast cancer in causation and therapy. Cancer, 58, 1808-1813.

Xiao, Y., Kang, J., Morgan, J., Leaf, A., 1995. Suppression of voltage-dependent $\mathrm{Na}^{+}$current by eicosapentaenoic acid in neonatal rat cardiac myocytes. Proc. Natl. Acad. Sci. USA, 92, 1100011004. 
Xiao, Y.-F., Gomez, A.-M., Morgan, J., Lederer, W., Leaf, A., 1997. Suppression of voltage-gated L-type $\mathrm{Ca}^{2+}$ currents by polyunsaturated fatty acids in adult and neonatal rat ventricular myocytes. Proc. Natl. Acad. Sci. USA, 94, 4182-4187.

Xiao, Y., Ke, Q., Chen, Y., Morgan, J., Leaf, A., 2004. Inhibitory effect of n-3 fish oil fatty acids on cardiac $\mathrm{Na}+\mathrm{Ca} 2+$ exchange currents in HEK293t cells. Biochem Biophys Res Commun. 321(1),116-123.

Xiao, Y.-F., Ke, Q., Wang, S.-Y., Auktor, K., Yang, Y., Wang, G., Morgan, J., Leaf, A., 2001. Single point mutations affect fatty acid block of human myocardial sodium channel $\alpha$ subunit $\mathrm{Na}^{+}$channels. Proc. Natl. Acad. Sci. USA, 98, 3606-3611.

Zhang Y., Morita, I., Yao, X., Murota, S., 1999. Pretreatment with eicosapentaenoic acid prevented hypoxia/reoxygenation-induced abnormality in endothelial gap junctional intercellular communication through inhibiting the tyrosine kinase activity. Prostaglandins Leukot. Essent. Fatty Acids., 61(1), 33-40. 

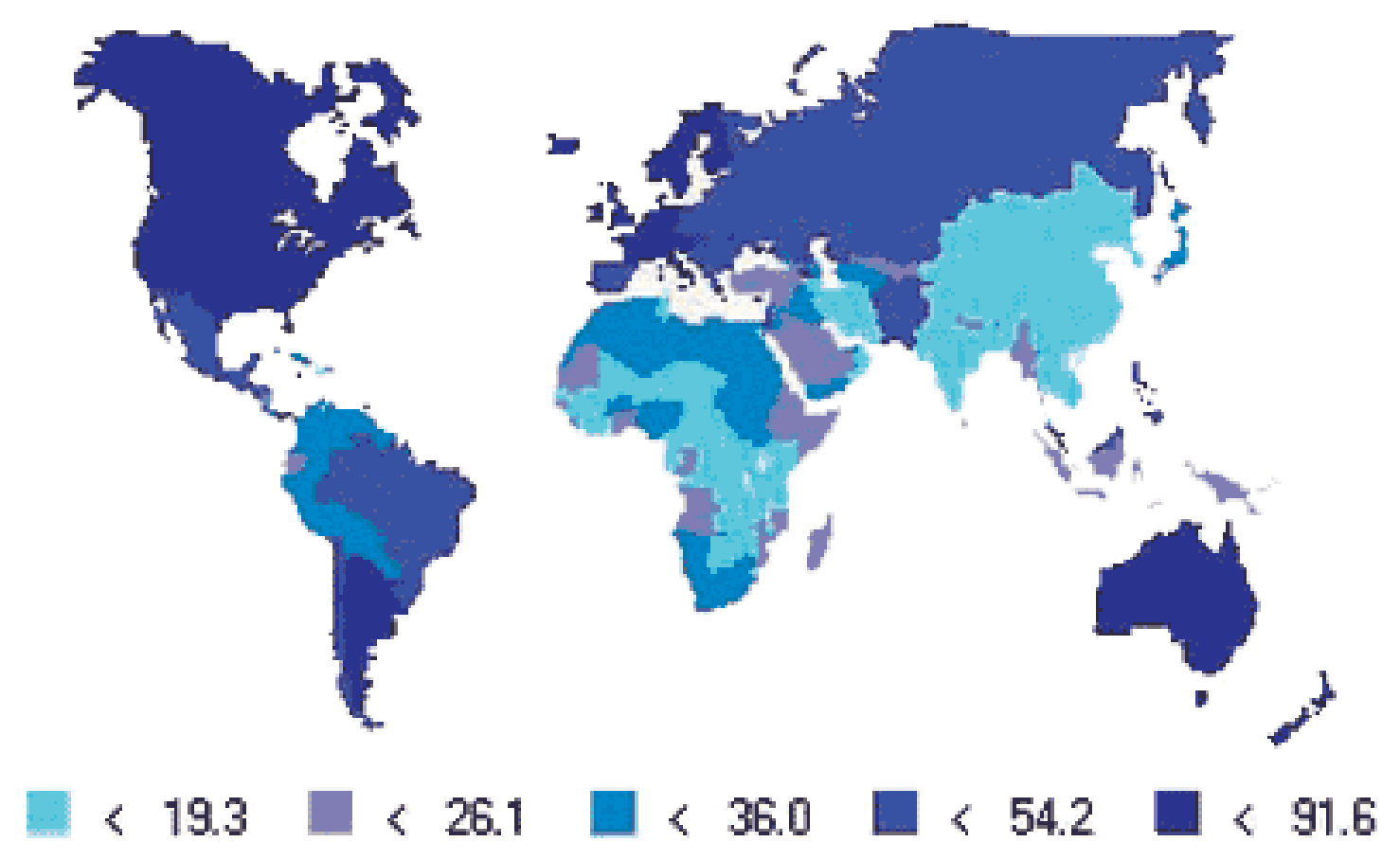

B
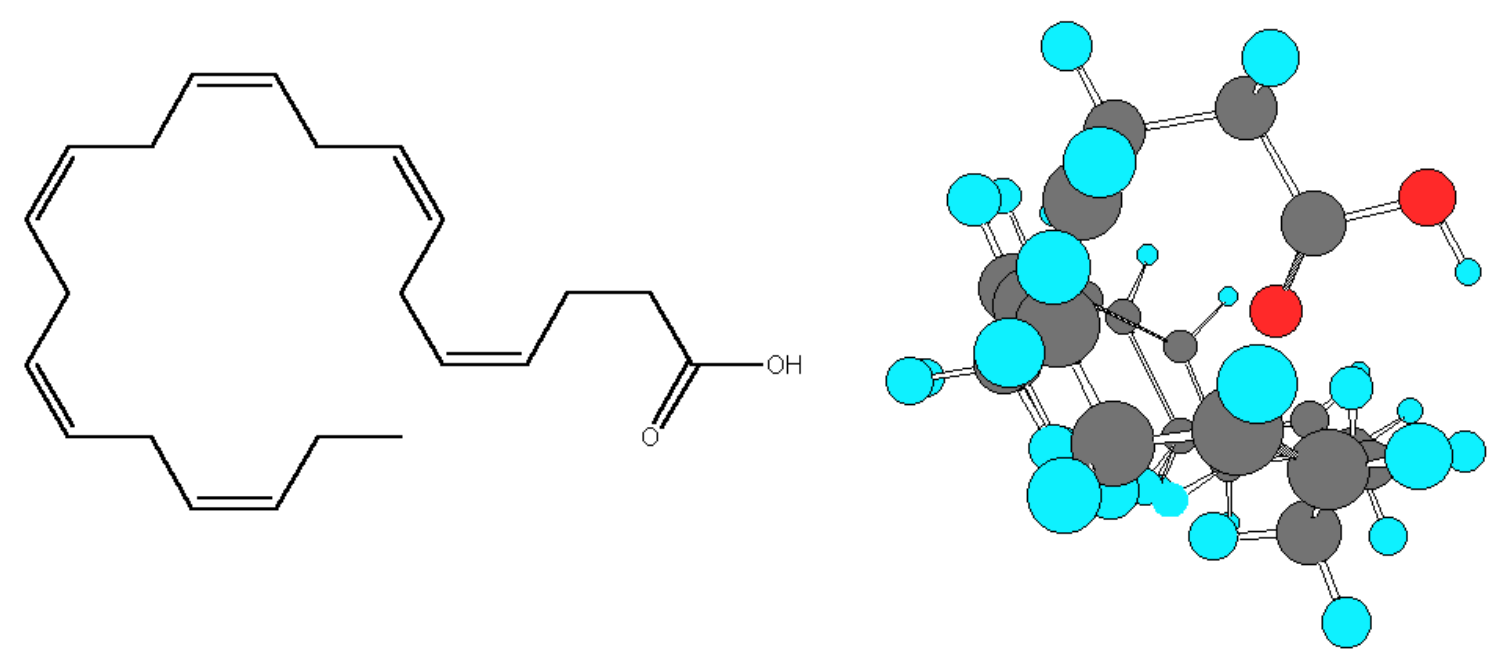

Figure 1. A, Repartition of women breast cancer incidence in the world. Incidence values are given per $100000 \quad$ women. From $\quad$ Globocan, $2000 . \quad$ (see http://www.inctr.org/publications/2002_v03_n01_s02.shtml. Valid on Jan. $\left.4^{\text {th }}, 2005\right)$. B, 2D (left) and 3D (right) structures of DHA. The coloured balls correspond to atoms as follows: gray, carbon; blue, hydrogen; red, oxygen. 

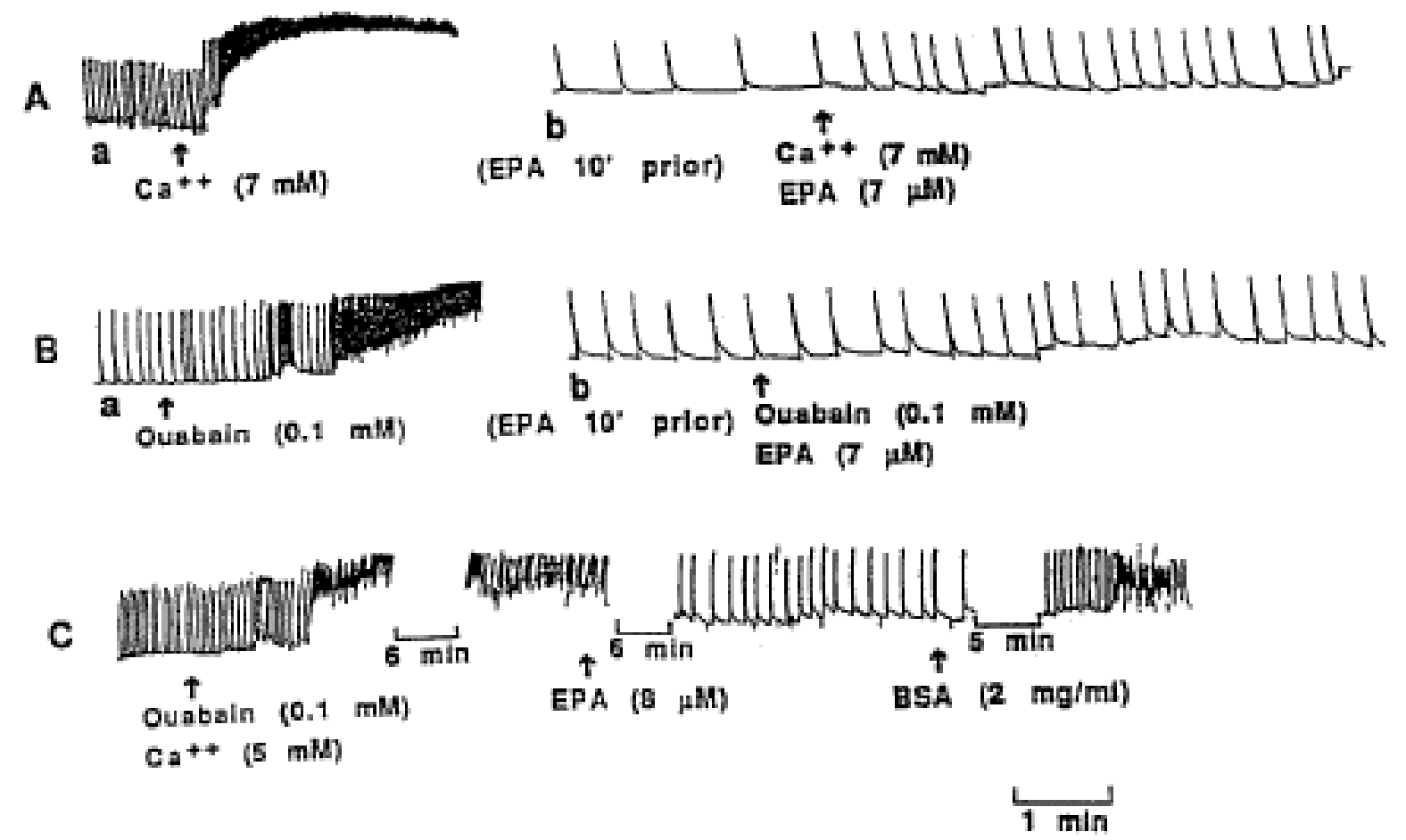

Figure 2: Prevention and termination of arrhythmias by EPA. Traces show the shortening of cultured neonatal cardiac rat myocytes. Perfusion with medium containing $7 \mathrm{mM} \mathrm{Ca}^{2+}(\mathrm{A}, \mathrm{a})$ or $100 \mu \mathrm{M}$ ouabain $(\mathrm{B}, \mathrm{a})$ induced contracture and tachyarrhythmias. Cells washed with medium containing $1.2 \mathrm{mM} \mathrm{Ca}^{2+}$ returned to their original beating rate (not shown). Myocytes were then perfused with medium containing $7 \mu \mathrm{M}$ EPA. When beating rate had slowed, addition of $7 \mathrm{mM}$ $\mathrm{Ca}^{2+}(\mathrm{A}, \mathrm{b})$ or $100 \mu \mathrm{M}$ ouabain $(\mathrm{B}, \mathrm{b})$ failed to induce contractures or tachyarrhythmias. Beating rates, slowed by EPA, returned to original by perfusion with albumin (not shown). C, tachyarrhythmias were induced by ouabain $(100 \mu \mathrm{M})$ plus $\mathrm{Ca}^{2+}(5 \mathrm{mM})$ in perfusing medium. Addition of EPA $(8 \mu \mathrm{M})$ terminated tachyarrhythmias. Subsequent addition of delipidated BSA $2 \mathrm{mg} / \mathrm{ml}$, still in presence of ouabain and high $\mathrm{Ca}^{2+}$ concentrations extracted free EPA and tachyarrhythmias resumed. From Kang \& Leaf, 1994. 

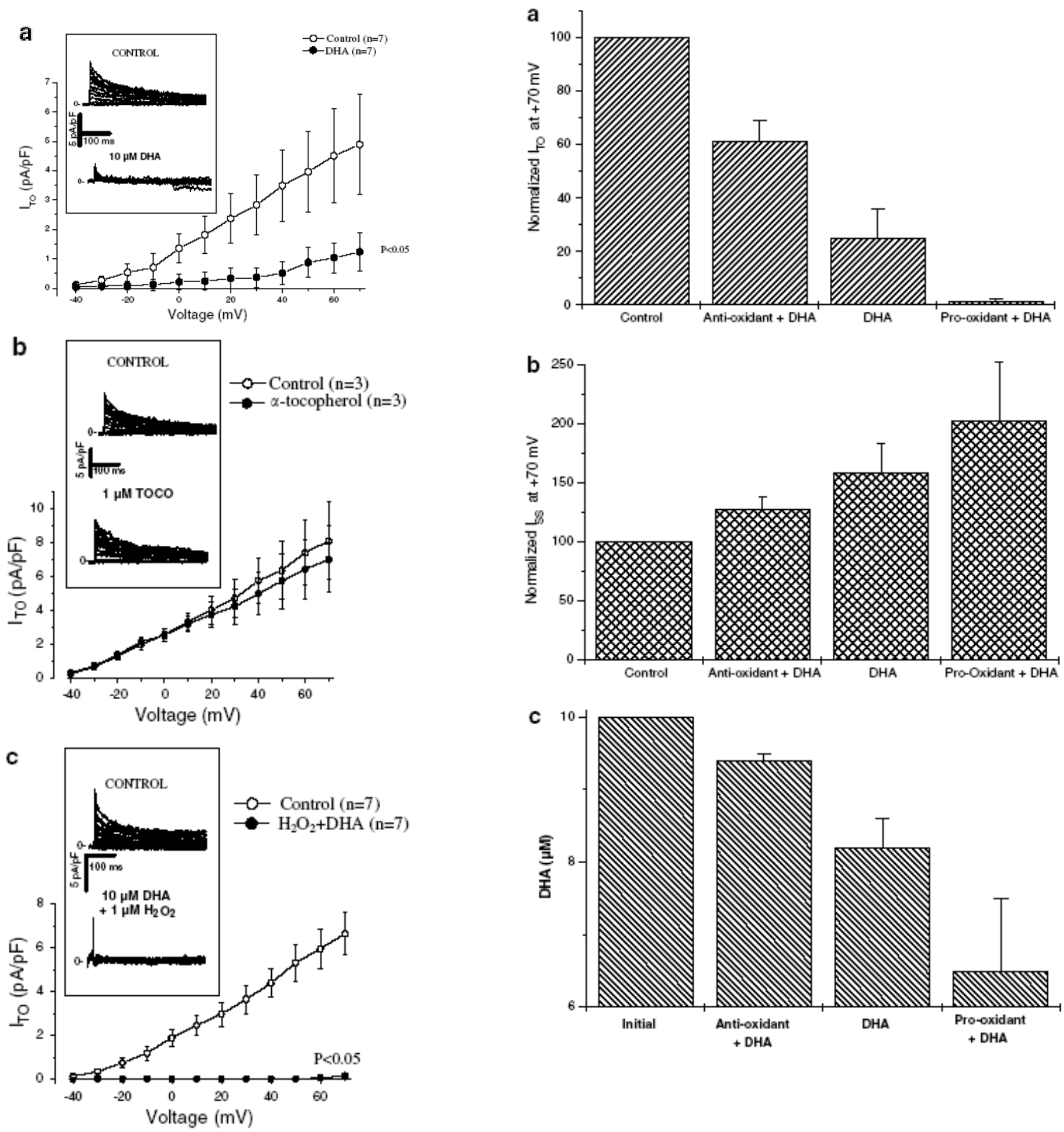

Figure 3. Comparison of the effects of $10 \mu \mathrm{M}$ DHA alone, in presence of $1 \mu \mathrm{M} \mathrm{H}_{2} \mathrm{O}_{2}$ or of $1 \mu \mathrm{M}$ vitamin $\mathrm{E}$ ( $\alpha$-tocopherol) on $\mathrm{I}_{\mathrm{TO}}(\mathrm{A})$ and $\mathrm{I}_{\mathrm{SS}}(\mathrm{A}, \mathrm{B})$. A, effects of DHA alone (a), in presence of an anti-oxidant ( $\alpha$-tocopherol) (b) or a pro-oxidant $\left(\mathrm{H}_{2} \mathrm{O}_{2}\right)$ (c) on $\mathrm{I}_{\mathrm{TO}}-\mathrm{V}$ relationship. B, Increasing the oxidative status of the Tyrode perfusing solution is associated with a larger effect of DHA on $\mathrm{I}_{\mathrm{TO}}$ (a) and $\mathrm{I}_{\mathrm{SS}}$ (b). Currents are expressed as mean \pm SEM after normalization to current in plain Tyrode 
solution. All the means are significantly different from each other $(\mathrm{P}<0.05)$. Bc, Concentrations of unperoxidized DHA in the different experimental conditions vs theoretical concentration. Initial: theoretical DHA concentration; Anti-oxidant = vitamin E; Pro-oxidant $=$ hydrogen peroxide. From Judé et al., 2003. 

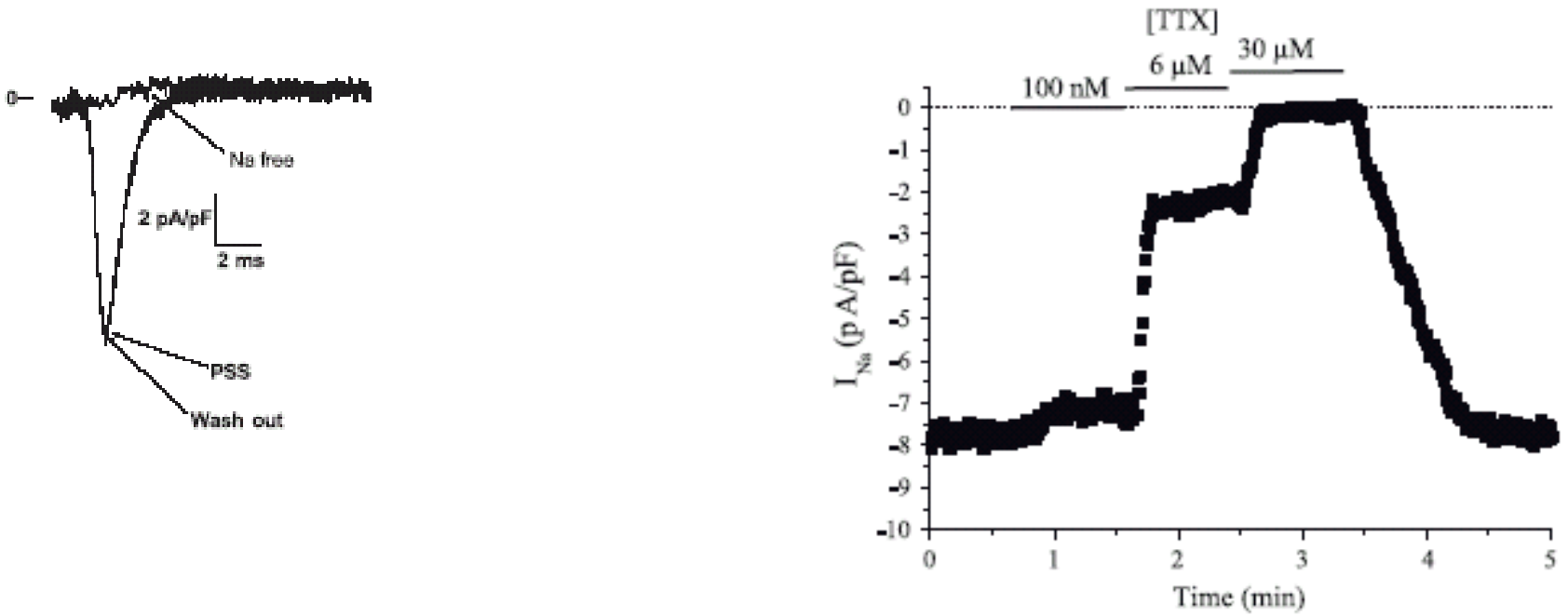

C

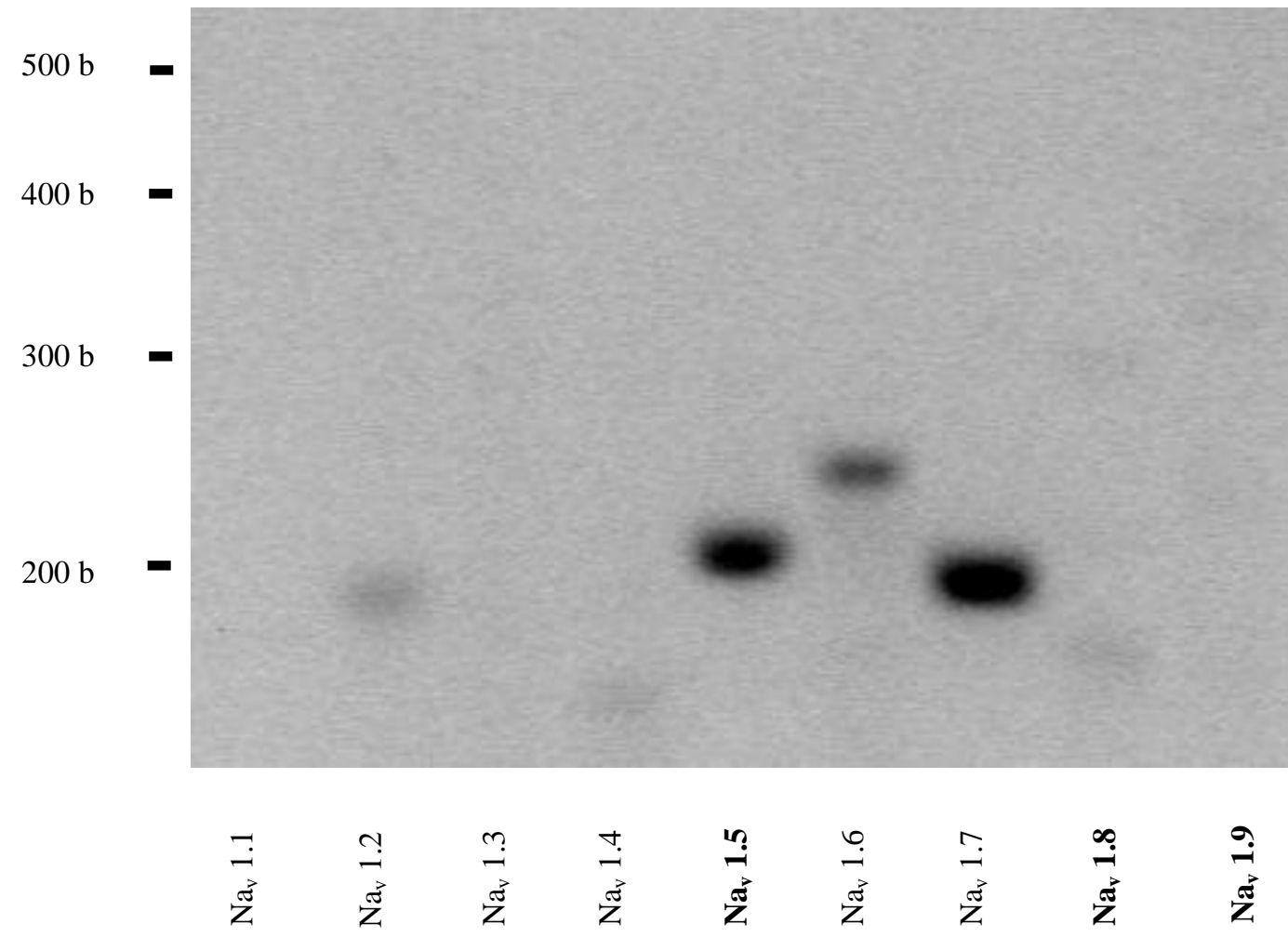

Figure 4. MDA-MD-231 invasive breast cancer cells express voltage-gated sodium channel. A, the inward current is triggered by a $30-\mathrm{ms}$ depolarisation from $-100 \mathrm{mV}$ to $-5 \mathrm{mV}$ and is sensitive to external sodium. B, the sodium current is sensitive to micromolar concentrations of TTX. C, RTPCR showing that the protein carrying the current is the Nav1.5 since it is the only TTX-R mRNA expressed (TTX-R are in bold). A and B from Roger et al., 2003. 


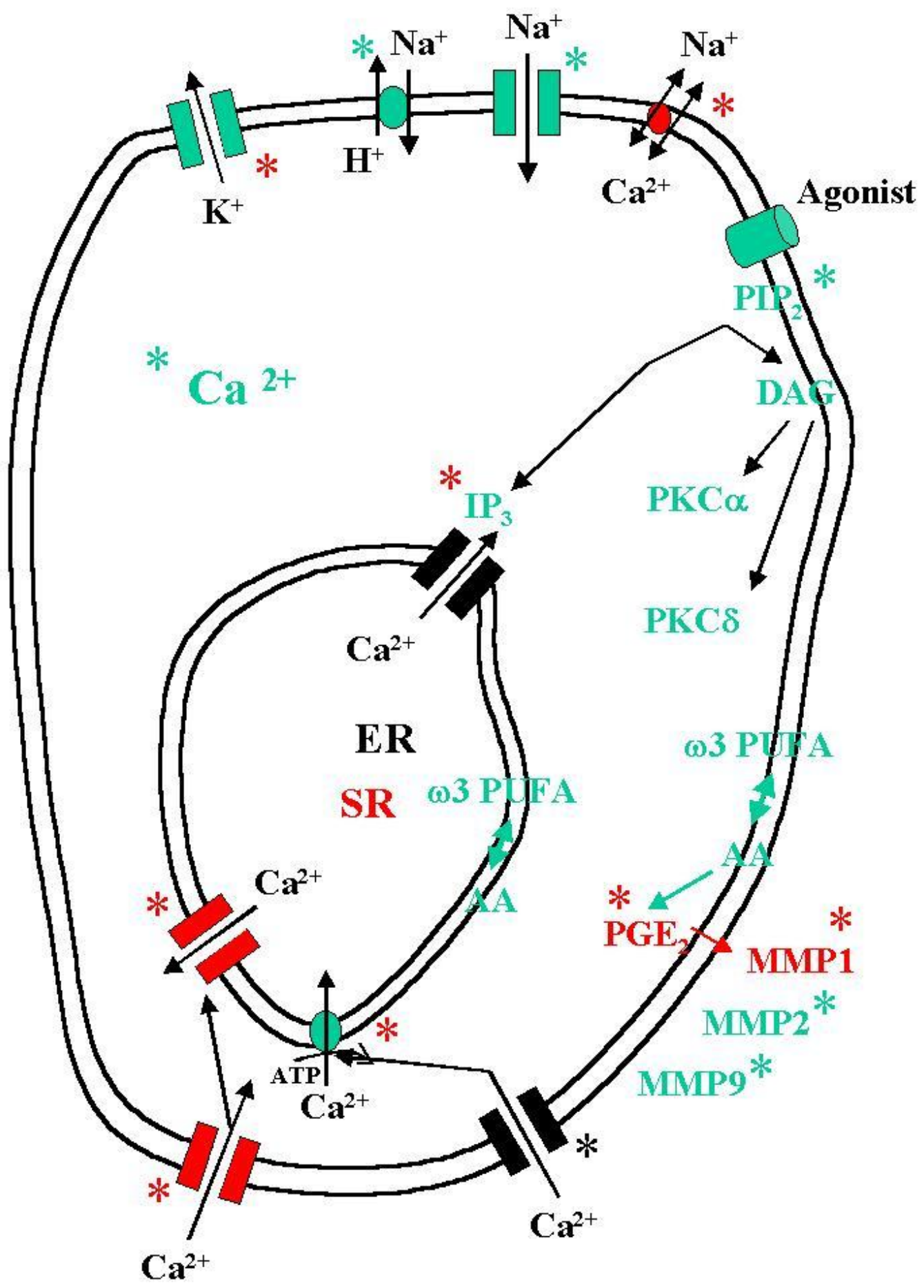

Figure 5. Schematic cell showing the different pathways which can be affected by $\omega-3$ LC-PUFAs. Specific components of cardiac cells are shown in red, of breast cancer cells in black and common components in green. Asterisks indicate the reported targets (direct or indirect) of $\omega-3$ LC-PUFAs in cardiac cells (red asterisks), cancer cells (black asterisks) and both kinds of cells (green asterisks). 